Check for updates

Cite this: RSC Adv., 2019, 9, 30585

Received 12th August 2019

Accepted 19th September 2019

DOI: $10.1039 / c 9 r a 06273 d$

rsc.li/rsc-advances

\section{Graphene-based plasmonic nanocomposites for highly enhanced solar-driven photocatalytic activities}

\author{
Rania E. Adam, (D) $\dagger^{\star * a}$ Ebrahim Chalangar, (D) $\dagger^{\mathrm{ab}}$ Mahsa Pirhashemi, ${ }^{\mathrm{c}}$ Galia Pozina, ${ }^{\mathrm{d}}$ \\ Xianjie Liu, ${ }^{d}$ Justinas Palisaitis, ${ }^{d}$ Håkan Pettersson, ${ }^{\text {abe }}$ Magnus Willander ${ }^{a}$ \\ and Omer Nur (D) a
}

High-efficiency photocatalysts are crucial for the removal of organic pollutants and environmental sustainability. In the present work, we report on a new low-temperature hydrothermal chemical method, assisted by ultrasonication, to synthesize disruptive plasmonic $\mathrm{ZnO} / g$ raphene/Ag/Agl nanocomposites for solar-driven photocatalysis. The plasmonic nanocomposites were investigated by a wide range of characterization techniques, confirming successful formation of photocatalysts with excellent degradation efficiency. Using Congo red as a model dye molecule, our experimental results demonstrated a photocatalytic reactivity exceeding $90 \%$ efficiency after one hour simulated solar irradiation. The significantly enhanced degradation efficiency is attributed to improved electronic properties of the nanocomposites by hybridization of the graphene and to the addition of Ag/Agl which generates a strong surface plasmon resonance effect in the metallic silver further improving the photocatalytic activity and stability under solar irradiation. Scavenger experiments suggest that superoxide and hydroxyl radicals are responsible for the photodegradation of Congo red. Our findings are important for the fundamental understanding of the photocatalytic mechanism of $\mathrm{ZnO} / \mathrm{graphene} / \mathrm{Ag} /$ $\mathrm{Agl} \mathrm{nanocomposites} \mathrm{and} \mathrm{can} \mathrm{lead} \mathrm{to} \mathrm{further} \mathrm{development} \mathrm{of} \mathrm{novel} \mathrm{efficient} \mathrm{photocatalyst} \mathrm{materials.}$

\section{Introduction}

Research on solar energy-driven photocatalysts is growing fast due to environmental concerns and to the need for utilization of sustainable energy resources. ${ }^{\mathbf{1 - 4}}$ So far, semiconductor-based nanostructures are among the most studied materials for photocatalytic purposes due to their remarkably high efficiency. ${ }^{5-9}$ However, many of these semiconductors suffer from issues with poor absorption of light and high recombination rates of photogenerated electron-hole $\left(\mathrm{e}^{-} / \mathrm{h}^{+}\right)$pairs.,10 Heterostructure materials offer the possibility of advanced bandgap engineering to drastically improve the scavenging of energy from the sunlight for degradation of harmful organic compounds and contaminants. Various heterostructure materials have been

${ }^{a}$ Department of Sciences and Technology, Linköping University, Campus Norrköping, SE-601 74 Norrköping, Sweden. E-mail: rania.elhadi.adam@liu.se

${ }^{b}$ School of Information Technology, Halmstad University, SE-301 18 Halmstad, Sweden

${ }^{c}$ Department of Chemistry, Faculty of Sciences, University of Mohaghegh Ardabili, P.O. Box 179, Ardabil, Iran

${ }^{d}$ Department of Physics, Chemistry, and Biology (IFM), Linköping University, 58183 Linköping, Sweden

${ }^{e}$ Solid State Physics and NanoLund, Lund University, SE-221 00 Lund, Sweden

$\dagger$ Both have contributed equally to the work and should be considered co-first authors. explored with the aim to find materials with enhanced photocatalytic properties under solar light irradiation. Zinc oxide ( $\mathrm{ZnO})$ is a remarkable photocatalyst that can be composited with other materials to improve visible light harvesting and, thus, the photocatalytic efficiency. ZnO-graphene nanocomposites are particularly interesting heterostructures with a capability of inhibiting the recombination of photogenerated charge carriers during the photocatalytic process. Graphene (GR) is a well-known 2D material consisting of carbon atoms arranged in a honeycomb lattice structure..$^{\mathbf{1 1 , 1 2}}$ It possesses many fundamentally interesting electronic properties such as zero bandgap, zero effective mass, high charge carrier mobility, large surface area, and high optical transparency over a very large spectral range from IR to UV, which makes it an excellent candidate for enhancing the performance of photocatalysts. $^{10,11,13-15}$ It was found that GR and GR oxide can significantly improve the separation efficiency of photogenerated $\mathrm{e}^{-} / \mathrm{h}^{+}$pairs in photocatalytic processes..$^{10,11,16-20}$ For instance, Tian et al. ${ }^{21}$ fabricated $\mathrm{ZnO}$ nanorods/reduced GR oxide nanocomposites for enhancing the photodegradation of methylene blue dye. Also, Sawant et al. ${ }^{22}$ showed an enhancement of the photodegradation capability of methylene orange and rhodamine $\mathrm{B}$ using $\mathrm{ZnO} / \mathrm{GR}$ nanosheets.

Many different metal-semiconductor nanostructures have been studied as plasmonic photocatalysts. ${ }^{6,23,24}$ Recently, Ag- 
based semiconductors exhibiting a strong surface plasmon resonance effect (SPR) ${ }^{23,25-29}$ were extensively investigated as visible light photocatalysts for degradation of organic pollutants and toxic dyes. In order to further increase the photocatalytic activity of the $\mathrm{ZnO} / \mathrm{GR}$ photocatalyst under visible light irradiation, a narrow bandgap silver halide e.g. silver iodide (AgI) can be added to the nanocomposite. ${ }^{25}$ The blending of AgI with $\mathrm{ZnO}$ shifts the absorption of the nanocomposite significantly towards the visible light region. ${ }^{11,27,30}$ In addition, the excellent conductivity of AgI nanostructures can promote electron transfer that suppresses $\mathrm{e}^{-} / \mathrm{h}^{+}$recombination and, thus, enhances the interfacial charge transfer. ${ }^{25}$ Therefore, it is expected that the addition of $\mathrm{Ag} / \mathrm{AgI}$ to $\mathrm{ZnO} / \mathrm{GR}$ would result in a new nanocomposite with excellent photocatalytic performance. So far, to the best of our knowledge, there are no reports on photocatalytic properties of nanocomposites comprising $\mathrm{Ag} /$ AgI and ZnO/GR with respect to degradation of CR dye under solar light irradiation.

In the present work, we report on new plasmonic $\mathrm{ZnO} / \mathrm{GR} /$ Ag/AgI nanocomposites with highly enhanced photocatalytic capability under simulated solar light irradiation. The nanocomposites were prepared via an ultrasonic-assisted hydrothermal solution-based procedure and used for photodegradation of CR dyes. First, ZnO/GR nanocomposites were prepared through hydrothermal growth of $\mathrm{ZnO}$ nanoparticles (NPs) on GR nanosheets. ${ }^{20}$ Subsequently, Ag/AgI NPs were grown on the $\mathrm{ZnO} / \mathrm{GR}$ nanocomposites via an ultrasonic irradiation method. ${ }^{20}$ Also, pristine $\mathrm{ZnO}$ NPs and $\mathrm{ZnO} / \mathrm{Ag} / \mathrm{AgI}$ nanocomposites were prepared as reference samples. The $\mathrm{ZnO} / \mathrm{GR} / \mathrm{Ag} / \mathrm{AgI}$ nanocomposite exhibits superior photocatalytic performance compared to $\mathrm{ZnO}$ NPs, ZnO/GR, and $\mathrm{ZnO} / \mathrm{Ag} / \mathrm{AgI}$ nanocomposites. The enhanced photodegradation of CR dyes is primarily attributed to increased light absorption and separation of photogenerated charge carriers by the unique heterojunctions formed between the $\mathrm{ZnO}, \mathrm{GR}$, and $\mathrm{Ag} / \mathrm{AgI}$ counterparts. We present a detailed model of the enhanced photocatalytic mechanism based on the calculated band structure profile of the $\mathrm{ZnO} / \mathrm{GR} / \mathrm{Ag} / \mathrm{AgI}$ heterojunctions.

\section{Experimental part}

\subsection{Materials}

All the chemicals used in this work were purchased from Sigma Aldrich and used without any further purification, including the multilayer GR powder, zinc acetate dihydrate $\left(\mathrm{Zn}\left(\mathrm{CH}_{3} \mathrm{COO}\right)_{2}\right.$ $\left.\cdot 2 \mathrm{H}_{2} \mathrm{O}\right)$, potassium hydroxide $(\mathrm{KOH})$, silver nitrate $\left(\mathrm{AgNO}_{3}\right)$, and sodium iodide (NaI). Deionized (DI) water was used in all steps.

\subsection{Samples preparation}

2.2.1 ZnO/GR. The $\mathrm{ZnO/GR}$ nanocomposite with a GR-toZnO weight ratio of 1:99 was synthesized by adding a $10 \mathrm{mg} \mathrm{L} \mathrm{L}^{-1}$ dispersion of GR powder in a zinc acetate dehydrate solution (0.01 M) in DI water. Subsequently, $\mathrm{KOH}(0.05 \mathrm{M})$ was added dropwise to the above solution at $60{ }^{\circ} \mathrm{C}$ in an ultrasonic bath and kept for 10 minutes. The obtained ZnO/GR nanocomposite was then washed in water and acetone and

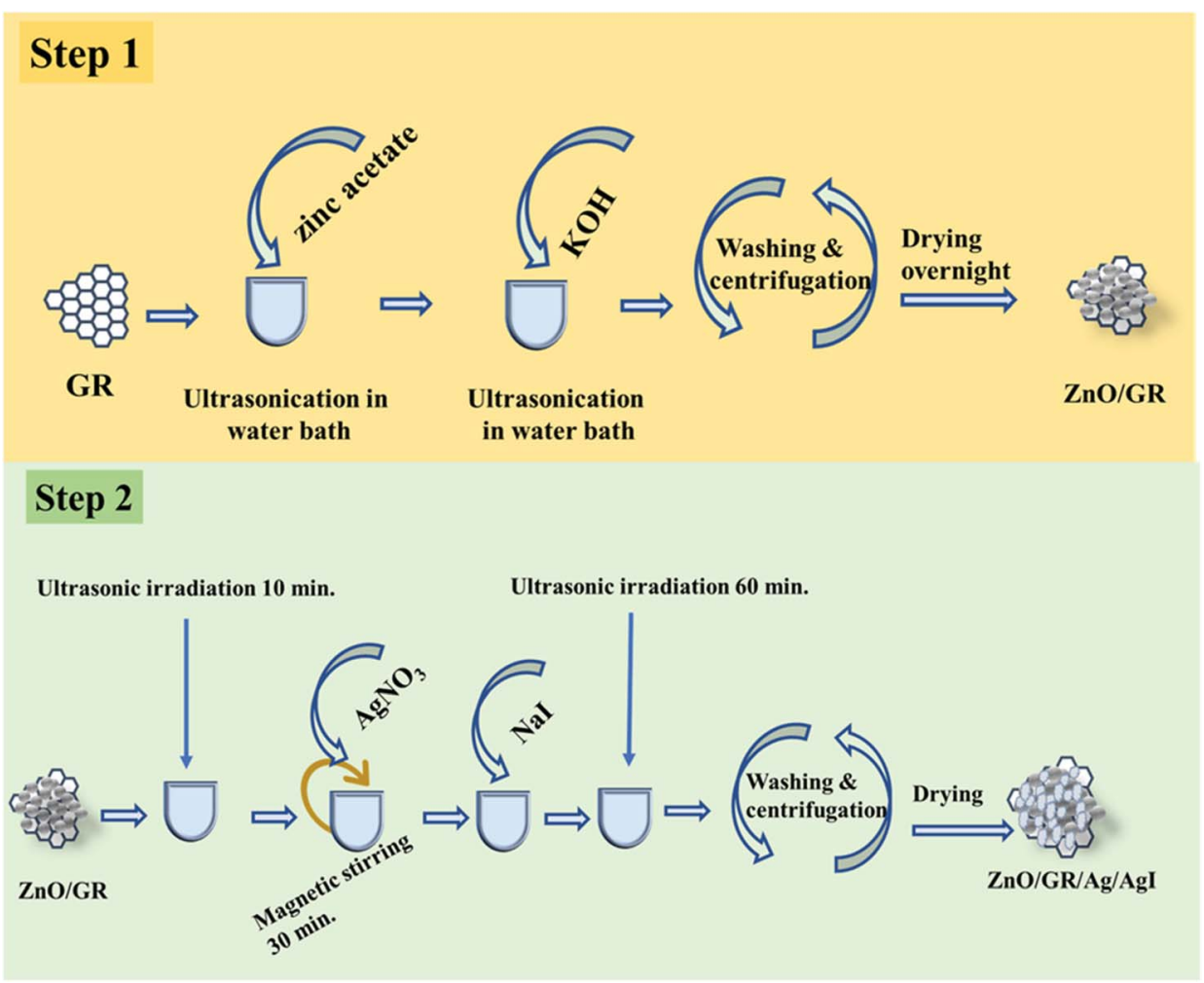

Fig. 1 Schematic diagram for preparation of $\mathrm{ZnO} / \mathrm{GR} / \mathrm{Ag} / \mathrm{Agl}$ nanocomposites. 
centrifuged at $3000 \mathrm{rpm}$ for 10 minutes three times, followed by drying in an oven at $120{ }^{\circ} \mathrm{C}$ overnight.

2.2.2 $\mathrm{ZnO} / \mathbf{G R} / \mathbf{A g} / \mathbf{A g I}$. To prepare the $\mathrm{ZnO} / \mathrm{GR} / \mathrm{Ag} / \mathrm{AgI}$ nanocomposites, $\mathrm{Ag} / \mathrm{AgI}$ was added to the as-prepared $\mathrm{ZnO} / \mathrm{GR}$ with three different weight ratios $X=10 \%, 20 \%$, and $30 \%$ forming the corresponding nanocomposite denoted $\mathrm{ZnO} / \mathrm{GR} / \mathrm{Ag} / \mathrm{AgI}(X \%)$. First, $\mathrm{ZnO} / \mathrm{GR}$ was dispersed into $200 \mathrm{~mL}$ of DI water with ultrasonic irradiation for 10 minutes and then $\mathrm{AgNO}_{3}$ was added to the suspension and stirred for 30 minutes. Next, an aqueous solution of NaI was added dropwise and the final suspension was ultrasonicated for one hour. The nanocomposites were separated by centrifugation and washed two times with DI water and acetone to remove any residuals, and finally dried in an oven at $75{ }^{\circ} \mathrm{C}$ for 6 hours. Fig. 1 shows the preparation steps for fabricating the $\mathrm{ZnO} /$ GR/Ag/AgI nanocomposites.

\subsection{Sample characterization}

Powder X-ray diffraction (XRD) was used to study the structural properties of the prepared samples using a Philips powder diffractometer $(1729 \mathrm{PW})$ equipped with a $\mathrm{Cu} \mathrm{K}(\alpha)$ radiation source at 40 $\mathrm{kV} / 40 \mathrm{~mA}$. The sample morphology was investigated with a fieldemission scanning electron microscope (FE-SEM), equipped with a Sigma 500 Gemini field emission gun operating at $10 \mathrm{kV}$. Samples for transmission electron microscopy (TEM) analysis were prepared by dispersing the obtained nanocomposites onto a lacey carbon film suspended by copper TEM grids. Scanning TEM (STEM) highangle annular dark-field imaging (HAADF), energy-dispersive X-ray spectroscopy (EDS) as well as TEM imaging were performed in the double-corrected Linköping FEI Titan ${ }^{3}$ 60-300, operated at 300 $\mathrm{kV}$. The microscope is equipped with image and probe Cs correctors and a monochromated high brightness XFEG gun and an efficient high solid angle Super-X EDX detector. The chemical composition of the samples was investigated by X-ray photoelectron spectroscopy (XPS) using a Scienta ESCA-200 spectrometer equipped with a monochromatic $\mathrm{Al} \mathrm{K}(\alpha)$ X-ray source with a photon energy of $1486.6 \mathrm{eV}$. The optical properties were analyzed by UV-Visible spectrophotometry (PerkinElmer Lambda 900 system) and cathodoluminescence (CL) spectroscopy (Gatan Mono CL4 system combined with FE-SEM). We have also carried out Mott-Schottky tests using a set-up comprising a PGSTAT302N workstation and a standard three-electrode system.

\subsection{Photocatalytic experiments}

The photocatalytic experiments were performed using a solar simulator (100 W ozone-free xenon lamp with a power of 1 sun). In brief, each sample $(0.05 \mathrm{~g})$ was mixed with $100 \mathrm{~mL}$ of $\mathrm{CR}$ dye solution with an initial concentration of $0.02 \mathrm{~g} \mathrm{~L}^{-1}$ and $\mathrm{pH} \sim 7$ to investigate the photocatalytic activities prior to exposure. These mixtures were then stirred for 30 minutes in dark to reach the adsorption-desorption equilibrium between the photocatalyst and
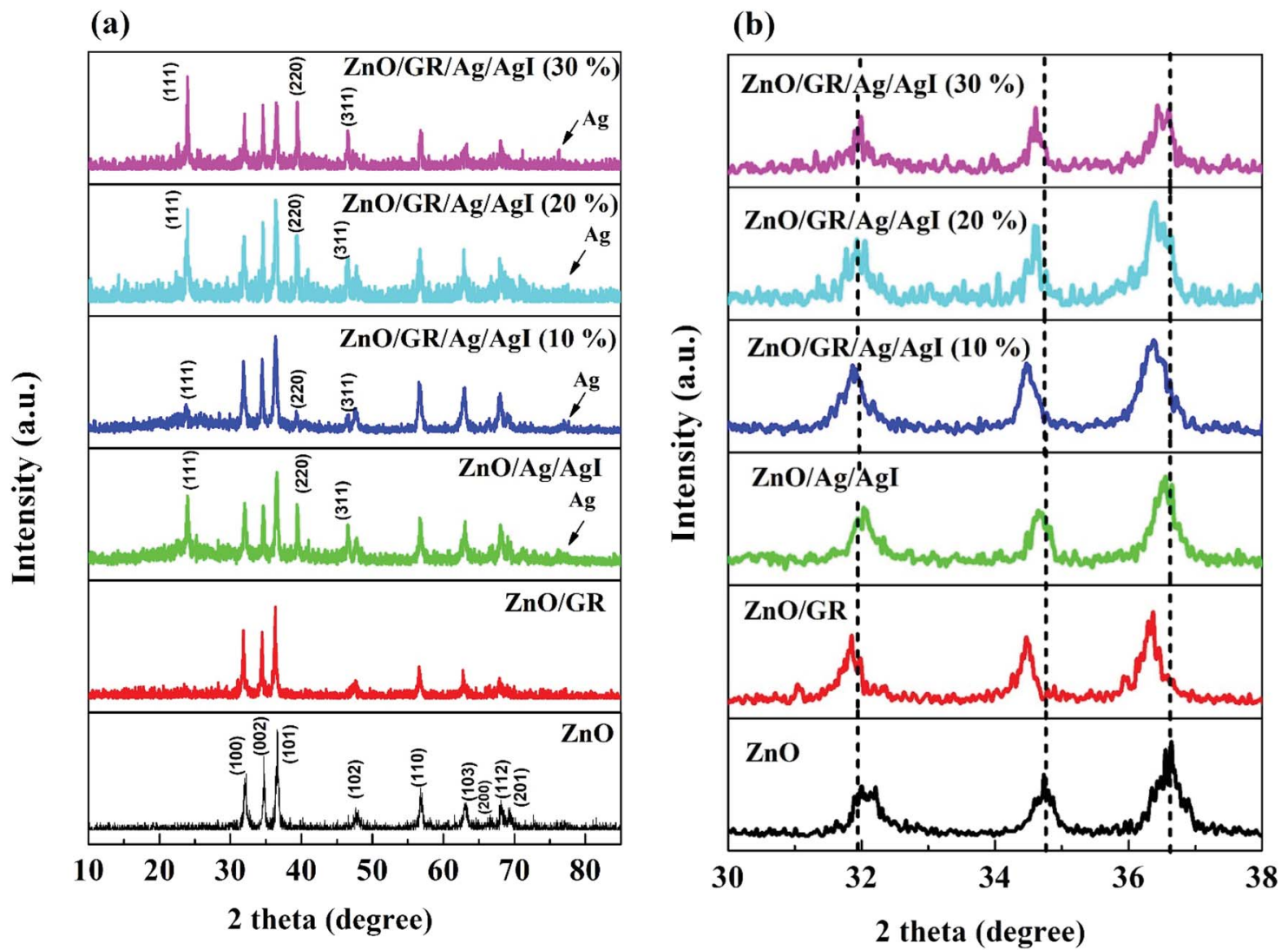

Fig. 2 (a) XRD spectra of pristine $\mathrm{ZnO} N P s, \mathrm{ZnO} / \mathrm{GR}, \mathrm{ZnO} / \mathrm{Ag} / \mathrm{Agl}$, and $\mathrm{ZnO} / \mathrm{GR} / \mathrm{Ag} / \mathrm{Agl}$ nanocomposites with a different weight percentage of Ag/Agl. (b) High-resolution XRD patterns revealing composition-dependent diffraction peak shifts. 
the dye molecules. After a given interval of irradiation time, a small amount of the mixtures was withdrawn and centrifuged. Finally, the UV-Vis absorbance spectra of the CR dye solution were recorded by the UV-Visible spectrophotometer.

\section{Results and discussion}

\subsection{Analysis of sample characteristics}

Fig. 2 shows the XRD spectra of pristine ZnO NPs, ZnO/GR, ZnO/ $\mathrm{Ag} / \mathrm{AgI}$, and $\mathrm{ZnO} / \mathrm{GR} / \mathrm{Ag} / \mathrm{AgI}$ nanocomposites. It can be observed in Fig. 2(a) that the pristine ZnO NPs exhibit characteristic peaks at $2 \theta$ values of $31.8^{\circ}, 34.6^{\circ}, 36.5^{\circ}, 47.8^{\circ}, 56.8^{\circ}, 63.0^{\circ}, 66.8^{\circ}$, $67.9^{\circ}$, and $69^{\circ}$, which correspond to the crystal planes (100), (002), (101), (102), (110), (103), (200), (112), and (201), respectively, which all belong to the pure hexagonal wurtzite phase of ZnO (JCPDS no. 36-1451). These results strongly imply that the samples are of good crystalline quality and free from defects. Similar XRD diffraction peaks were in fact observed from the $\mathrm{ZnO} / \mathrm{GR}$ nanocomposites. The fact that no diffraction peaks from carbon species were observed can be attributed to the low amount of GR $(1 \mathrm{wt} \%)$ in the samples ${ }^{18,19}$ and to the relatively low diffraction intensity of GR. ${ }^{31}$ The presence of GR in the nanocomposites was identified by TEM and XPS analysis (see below). The addition of AgI nanoparticles to the $\mathrm{ZnO}$ and $\mathrm{ZnO} /$ GR nanocomposites show diffraction patterns at $2 \theta$ values of $23.9^{\circ}, 39.2^{\circ}$, and $46.0^{\circ}$, which could be related to the crystal planes (111), (220), and (311), respectively, of the cubic AgI structure (JCPDS no 01-0503). ${ }^{27}$ This conclusion is supported by the observed increase in the intensity of the AgI-related peaks with increasing AgI content. In addition, a small peak at $\sim 77^{\circ}$ was observed in $\mathrm{ZnO} / \mathrm{Ag} / \mathrm{AgI}$ and various $\mathrm{ZnO} / \mathrm{GR} / \mathrm{Ag} / \mathrm{AgI}$ nanocomposites, which can be assigned to the reflections of $\mathrm{Ag}^{\mathrm{O}}$ (JCPDS no 65-2871) 27,32 $^{2}$ produced during the sample preparation. The effect of GR and Ag/AgI on the crystal structure of the pristine ZnO NPs was examined by more accurate XRD measurements in the region of $30-40^{\circ}$ as shown in Fig. 2(b). A small shift of the XRD peaks towards smaller angles was not only observed for the $\mathrm{ZnO} / \mathrm{GR}$ nanocomposites compared to the pristine ZnO NPs, but in fact detected for all GR incorporated nanocomposites. This shift indicates that the lattice constants of $\mathrm{ZnO}$ and $\mathrm{Ag} / \mathrm{AgI}$ NPs have changed due to the presence of the carbonaceous material, in agreement with previous reports. ${ }^{33,34}$ The crystallite size of the NPs can be calculated by the Scherrer equation: ${ }^{35}$

$$
D=\frac{k \lambda}{\beta_{h k l} \cos \theta}
$$

Here $D$ is the crystallite size of the ZnO NPs, $\lambda$ is the X-ray wavelength, $\theta$ is the Bragg diffraction angle, $\beta$ is the full width at half maximum of the diffraction peak corresponding to the
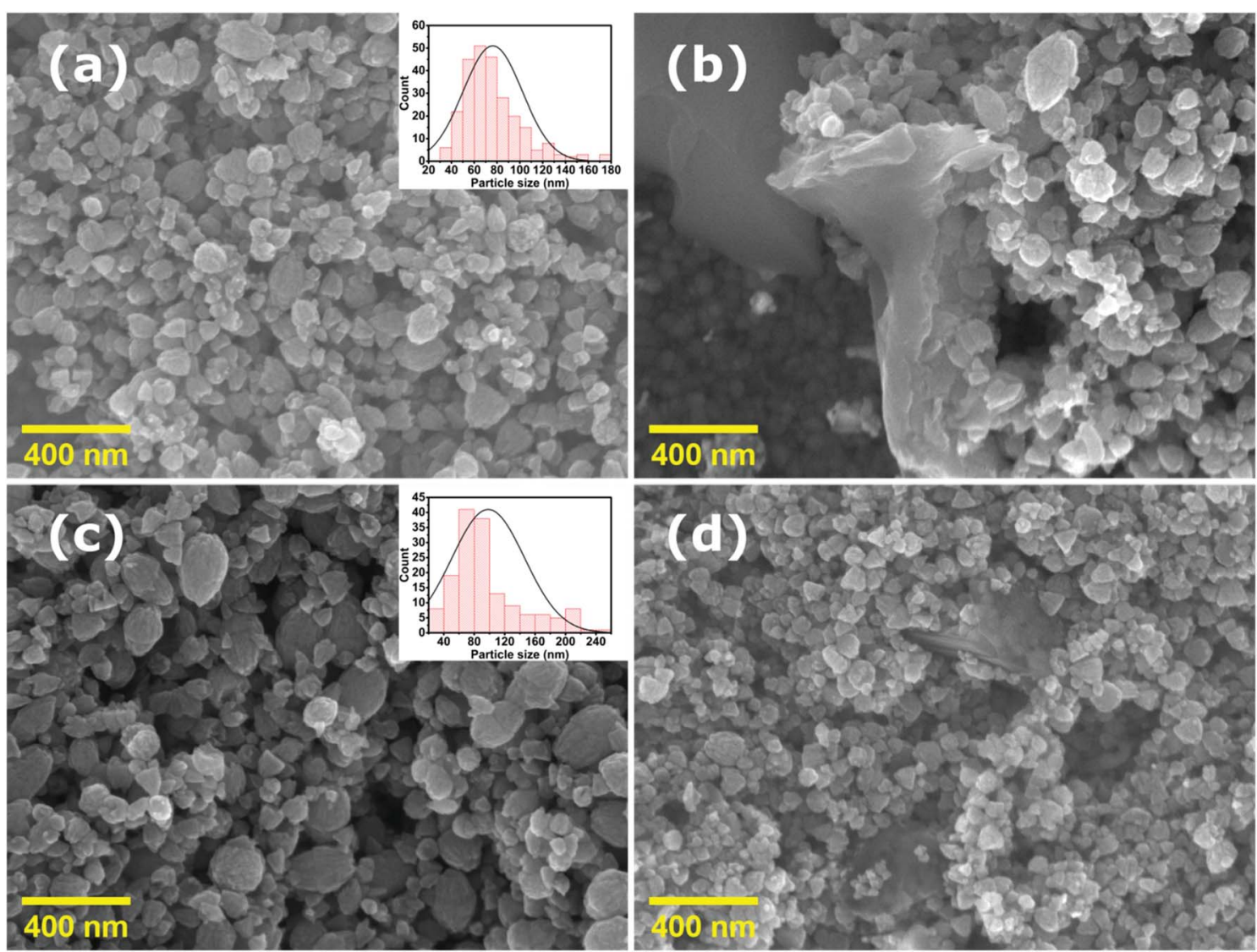

Fig. 3 FE-SEM images of (a) pristine ZnO NPs, (b) ZnO/GR, (c) ZnO/Ag/Agl, and (d) ZnO/GR/Ag/Agl (20\%) nanocomposites. The insets show the size distribution of the NPs. 


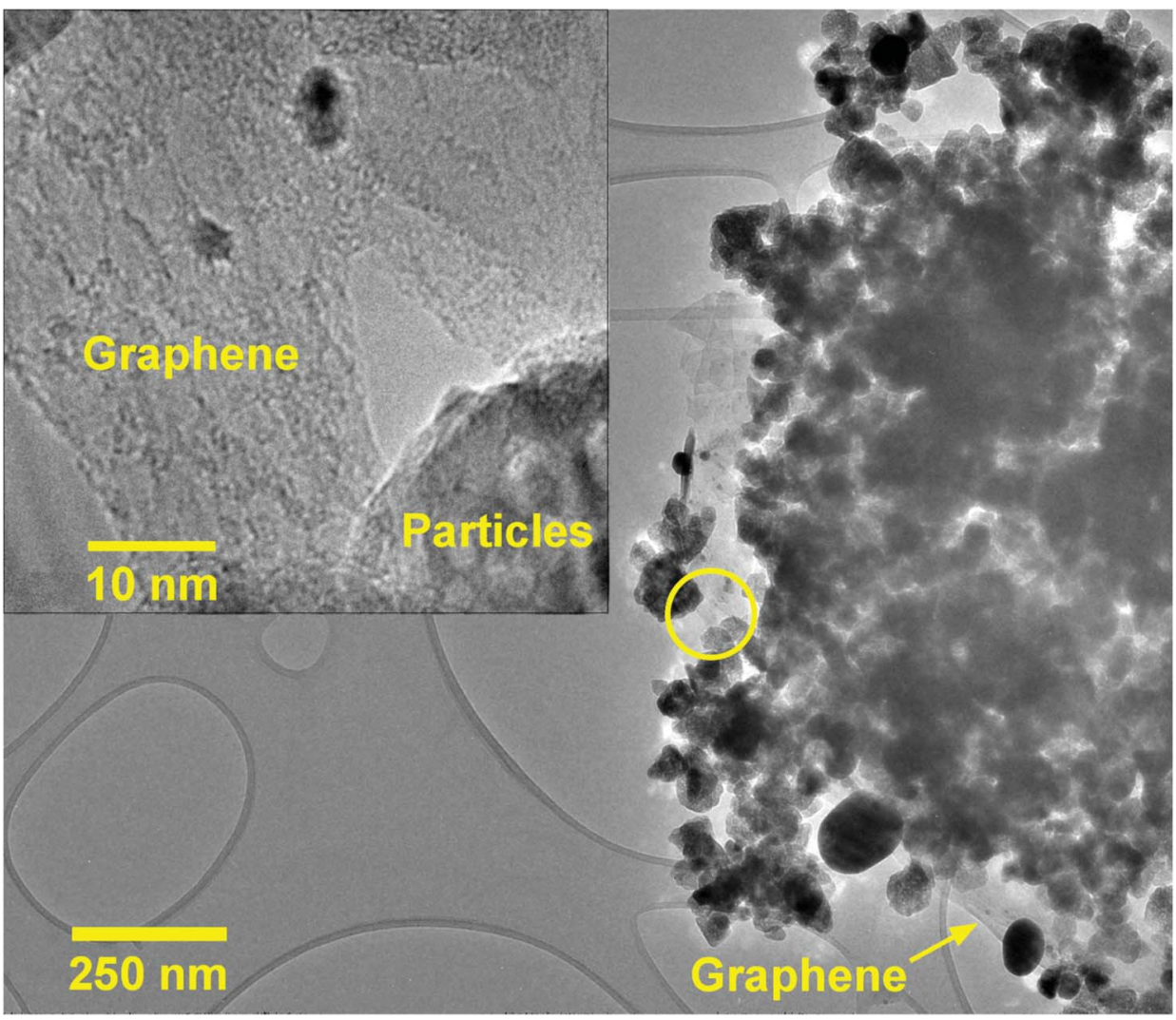

Fig. 4 TEM image of $\mathrm{ZnO} / \mathrm{GR} / \mathrm{Ag} / \mathrm{Agl}(20 \%)$ nanocomposites. The inset shows the conjunction of GR and particles (ZnO or Ag/Agl) at higher magnification (region marked by the yellow circle in the main image).

(101) plane, and $k$ is the Scherrer constant equal to 0.9. It was found that the crystallite size of ZnO NPs is increased slightly after the addition of the Ag/AgI from 17 to $20 \mathrm{~nm}$.
Fig. 3 shows FE-SEM images of the synthesized (a) pure $\mathrm{ZnO}$, (b) $\mathrm{ZnO} / \mathrm{GR}$, (c) $\mathrm{ZnO} / \mathrm{Ag} / \mathrm{AgI}$, and (d) $\mathrm{ZnO} / \mathrm{GR} / \mathrm{Ag} / \mathrm{AgI}(20 \%)$ samples. The pure ZnO NPs sample shows a uniform size

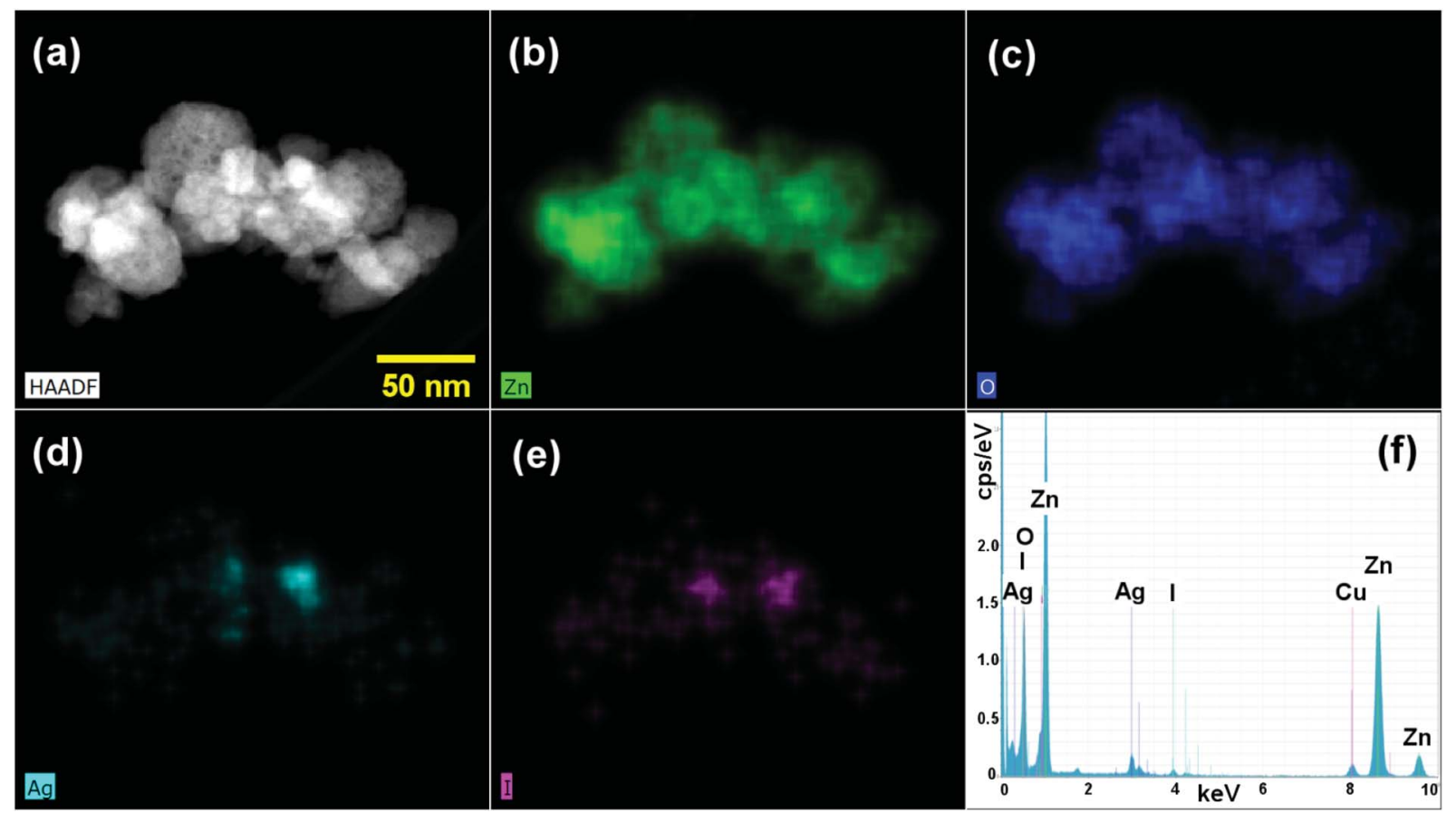

Fig. 5 (a) STEM-HAADF image of a ZnO/GR/Ag/Agl (20\%) nanocomposite, (b-e) STEM-EDS elemental maps displaying Zn, O, Ag, and I distributions, respectively, and (f) integrated EDS spectra. 
distribution as compared to the $\mathrm{ZnO} / \mathrm{Ag} / \mathrm{AgI}$ and $\mathrm{ZnO} / \mathrm{GR} / \mathrm{Ag} / \mathrm{AgI}$ (20\%) nanocomposites. The average size of the ZnO NPs was found to be $\sim 80 \mathrm{~nm}$, as estimated from the size distribution inset in (a). The average NPs size increased significantly to $\sim 100 \mathrm{~nm}$ (inset in (c)) when Ag/AgI was added to the ZnO NPs, which reflects the formation of $\mathrm{ZnO} / \mathrm{Ag} / \mathrm{AgI}$ agglomerates. The particle size observed in the FE-SEM images is much larger than that extracted from the XRD measurements, indicating a polycrystalline structure of the NPs.

TEM investigations confirm the conjunction of NPs and GR nanoplatelets in $\mathrm{ZnO} / \mathrm{GR} / \mathrm{Ag} / \mathrm{AgI}$ (20\%) nanocomposites as shown in Fig. 4. The GR nanoplatelets act as a substructure to assemble the nanoparticles enabling an electrical bridge between them. Additionally, it was observed that the GR nanoplatelets have different size and shape caused by the ultrasonic irradiation during the synthesis procedures.

The elemental distribution of the $\mathrm{ZnO} / \mathrm{GR} / \mathrm{Ag} / \mathrm{AgI}(20 \%)$ nanocomposites were examined using STEM-HAADF imaging (Fig. 5(a)) and STEM-EDS elemental mapping (Fig. 5(b-e)). The integrated EDS spectra, extracted from EDS maps, confirmed the presence of $\mathrm{Zn}, \mathrm{O}, \mathrm{Ag}$, and $\mathrm{I}$ elements in the nanocomposites. The corresponding elemental EDS maps revealed that the cluster of NPs forming the nanocomposite is mainly composed of $\mathrm{ZnO}$, while $\mathrm{Ag} / \mathrm{AgI}$ NPs are present in localized areas of the cluster. Carbon mapping did not display any spectral signatures from GR due to overlap with the underlying carbon support grid (not shown). It is worth noting that a better distribution of the elements in the nanocomposites provides a stronger bond between different counterparts. This leads to a more efficient generation and separation of charge carriers under solar irradiation, which in turn leads to excellent photocatalytic activities and higher photodegradation efficiency.

Furthermore, the chemical oxidation state of the elements in the $\mathrm{ZnO} / \mathrm{GR} / \mathrm{Ag} / \mathrm{AgI}$ (20\%) nanocomposite was identified by XPS analysis. From the XPS survey scan spectrum in Fig. 6(a) we could clearly identify the existence of $\mathrm{Zn}, \mathrm{O}, \mathrm{C}, \mathrm{Ag}$, and I in the nanocomposite. The high resolution of the $\mathrm{C}$ 1s spectrum shown in Fig. 6(b) was deconvoluted into three Gaussian peaks. Besides the $\mathrm{C}-\mathrm{C}$ bond peak at $284.79 \mathrm{eV}$, which demonstrates the introduced impurities from the surface contamination, ${ }^{36}$ there are two dominant peaks at 285.57 and $288.71 \mathrm{eV}$ assigned to $\mathrm{C}-\mathrm{O}-\mathrm{C}$ and $\mathrm{C}=\mathrm{O}$ bonds, ${ }^{11,36,37}$
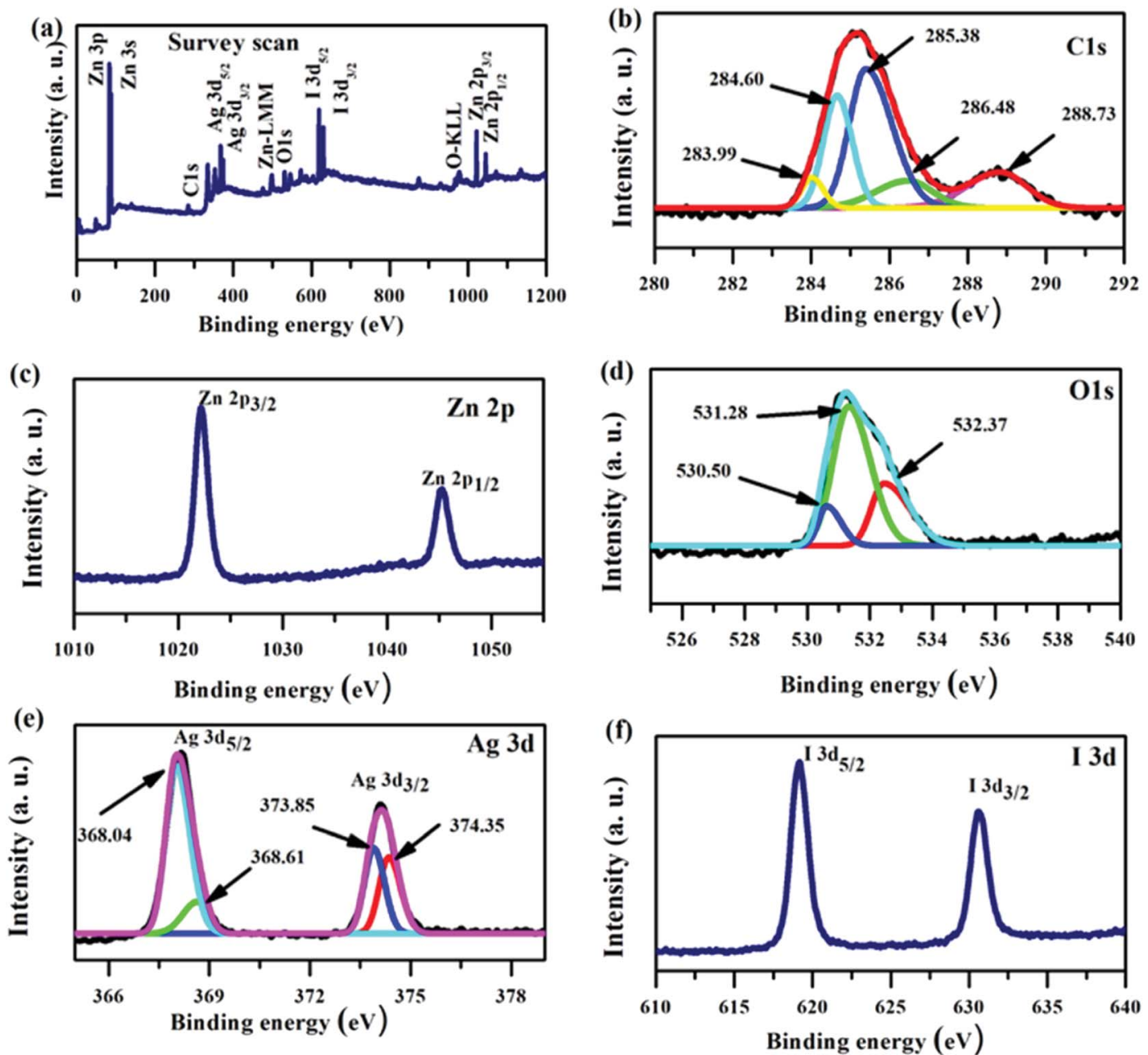

Fig. 6 XPS spectra for a ZnO/GR/Ag/Agl (20\%) nanocomposite. (a) Survey scan, and high resolution core level spectra of (b) C 1s, (c) Zn 2p, (d) O 1s, (e) Ag 3d, and (f) I 3d. 
respectively. As shown in Fig. 6(c), the XPS core level spectrum of Zn $2 \mathrm{p}$ is composed of two peaks centered at 1022.16 and $1045.23 \mathrm{eV}$, which are ascribed to the binding energy of $\mathrm{Zn} 2 \mathrm{p}_{3 / 2}$ and $\mathrm{Zn} 2 \mathrm{p}_{1 / 2}$ respectively. ${ }^{38}$ The core-level spectrum of $\mathrm{O} 1 \mathrm{~s}$ is presented in Fig. 6(d) and it is divided into two Gaussian fitted peaks. The peak centered at $530.50 \mathrm{eV}$ corresponds to oxygen in the ZnO NPs lattice in the nanocomposite structure..$^{37,39,40}$ The peak at $532.37 \mathrm{eV}$ can be ascribed to oxygen bonded to carbon atoms (the functional group present on GR) and also to the hydroxyl group adhering to the surface of nanocomposite. ${ }^{41,42}$ The XPS spectrum of Ag 3d is shown in Fig. 6(e). The main peaks at 368.13 and $374.06 \mathrm{eV}$ are assigned to $\mathrm{Ag} 3 \mathrm{~d}_{5 / 2}$ and $\mathrm{Ag} 3 \mathrm{~d}_{3 / 2}$, respectively. The $\mathrm{Ag} 3 \mathrm{~d}_{5 / 2}$ is further divided into two peaks at 367.82 and $368.28 \mathrm{eV}$ and the $\mathrm{Ag} 3 \mathrm{~d}_{3 / 2}$ peak is also divided into two peaks at 373.79 and $374.32 \mathrm{eV}$. The low energy peaks at 367.82 and $373.79 \mathrm{eV}$ are attributed to $\mathrm{Ag}^{+}$, whereas the peaks at 368.28 and $374.32 \mathrm{eV}$ are related to metallic $\mathrm{Ag}^{0.27,43}$ Accordingly, metallic $\mathrm{Ag}^{0}$ is produced at the surface of the $\mathrm{ZnO} / \mathrm{GR} /$ $\mathrm{Ag} / \mathrm{AgI}(20 \%)$ photocatalyst during the sample preparation, an observation consistent with the XRD results shown in Fig. 2(a). The chemical state of the I element, which is present in the form of $\mathrm{I}^{-}$ ions in the nanocomposite, is revealed in Fig. 6(f). Two clearly resolved peaks related to $\mathrm{I} 3 \mathrm{~d}_{5 / 2}$ and $\mathrm{I} 3 \mathrm{~d}_{3 / 2}$ are located at 619.02 and $630.58 \mathrm{eV}$, respectively. ${ }^{30}$

The optical characteristics of the nanocomposites were examined by UV-Vis spectroscopy and CL measurements. The UV-Vis absorbance spectra of ZnO NPs, ZnO/GR, ZnO/ Ag/AgI, and $\mathrm{ZnO} / \mathrm{GR} / \mathrm{Ag} / \mathrm{AgI}$ nanocomposites with different weight percent of Ag/AgI are shown in Fig. 7(a). It is clear that pure ZnO NPs exhibit a strong interband absorption edge around $400 \mathrm{~nm}$. The weak absorbance in the visible region is attributed to the presence of native point defects. ${ }^{29}$ The addition of GR to $\mathrm{ZnO}$ slightly redshifts the absorbance edge. This redshift can be explained by the influence of GR on the surface electric charge in the $\mathrm{ZnO} / \mathrm{GR}$ photocatalyst. ${ }^{10,44}$ In the case of $\mathrm{ZnO} / \mathrm{GR} / \mathrm{Ag} / \mathrm{AgI}$ nanocomposites, a broader absorbance is observed in the visible region $(\lambda>$ $400 \mathrm{~nm}$ ) which increases with the weight percent of Ag/AgI. Therefore, the blending of Ag/AgI into the nanocomposite can increase its photocatalytic performance under solar irradiation. The observed absorbance peak at $\lambda=430 \mathrm{~nm}$ is assigned to the surface plasmon absorption of the Ag/AgI NPs, indicating the presence of $\mathrm{Ag}^{0}$ at the surface of the nanocomposites. ${ }^{45}$ As a result, due to contributions from different counterparts, the fabricated plasmonic nanocomposite displays the highest optical absorbance, which is beneficial for the photocatalytic performance under solar irradiation. Fig. 7(b) shows CL spectra of $\mathrm{ZnO}, \mathrm{ZnO} / \mathrm{GR}$, $\mathrm{ZnO} / \mathrm{Ag} / \mathrm{AgI}$, and $\mathrm{ZnO} / \mathrm{GR} / \mathrm{Ag} / \mathrm{AgI}$ (20\%) samples, measured at room temperature. Interestingly, all samples exhibit a broad emission band covering the whole visible region with a luminescence peak centered at $\sim 600 \mathrm{~nm}$. This band can be attributed to radiative transitions associated with intrinsic deep levels such as oxygen vacancies and interstitials $\left(\mathrm{V}_{\mathrm{O}}, \mathrm{O}_{\mathrm{i}}\right)$, as well as to the presence of hydroxyl groups at the surface of the ZnO NPs. ${ }^{46-48}$ In addition, the observed peak at $\lambda=430 \mathrm{~nm}$ is attributed to surface plasmonenhanced luminescence, induced by the Ag/AgI NPs, in agreement with the UV-Vis spectrum in Fig. 7(a). The $\mathrm{ZnO} /$ GR/Ag/AgI (20\%) nanocomposite exhibits broader band luminescence than that of the pure $\mathrm{ZnO} \mathrm{NPs}$ and $\mathrm{ZnO} / \mathrm{GR}$, again consistent with the results presented in Fig. 7(a). Evidently, the presence of Ag/AgI has a significant positive effect on the emission properties in the visible region, which in turn is expected to improve the photocatalytic capability of the nanocomposite.

\subsection{Photocatalytic performance}

3.2.1 Photodegradation of toxic wastewater. We studied the photocatalytic activities of $\mathrm{ZnO}, \mathrm{ZnO} / \mathrm{GR}, \mathrm{ZnO} / \mathrm{Ag} / \mathrm{AgI}$ and $\mathrm{ZnO} / \mathrm{GR} / \mathrm{Ag} / \mathrm{AgI}$ samples through the degradation of CR dye under simulated solar irradiation. Fig. 8(a-f) shows the recorded UV-Vis absorbance of the CR dye mixed with the nanocomposite in 15 min steps of up to 60 min irradiation. First, the nanocomposite/CR dye was kept in dark for $30 \mathrm{~min}$ to reach the adsorption-desorption equilibrium state between the photocatalysts and CR molecules. Then the light was turned on, and the absorbance spectra were recorded after each 15 min step for all samples. It is well-known that carbon-based materials have
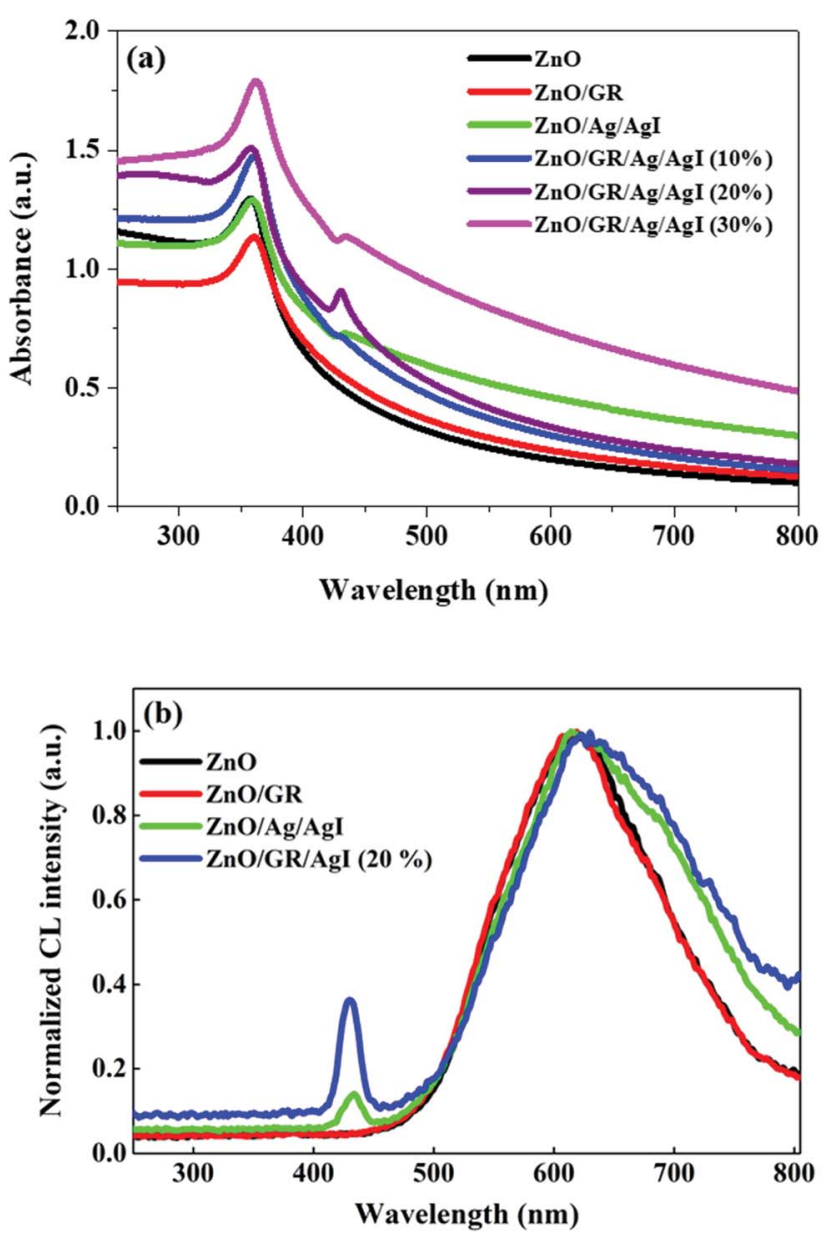

Fig. 7 (a) UV-Vis absorbance spectra of pristine $\mathrm{ZnO} N P s, \mathrm{ZnO} / \mathrm{GR}$, $\mathrm{ZnO} / \mathrm{Ag} / \mathrm{Agl}$, and $\mathrm{ZnO} / \mathrm{GR} / \mathrm{Ag} / \mathrm{Agl}$ nanocomposites with a different weight percentage of $\mathrm{Ag} / \mathrm{Agl}$, and (b) corresponding $\mathrm{CL}$ spectra. 

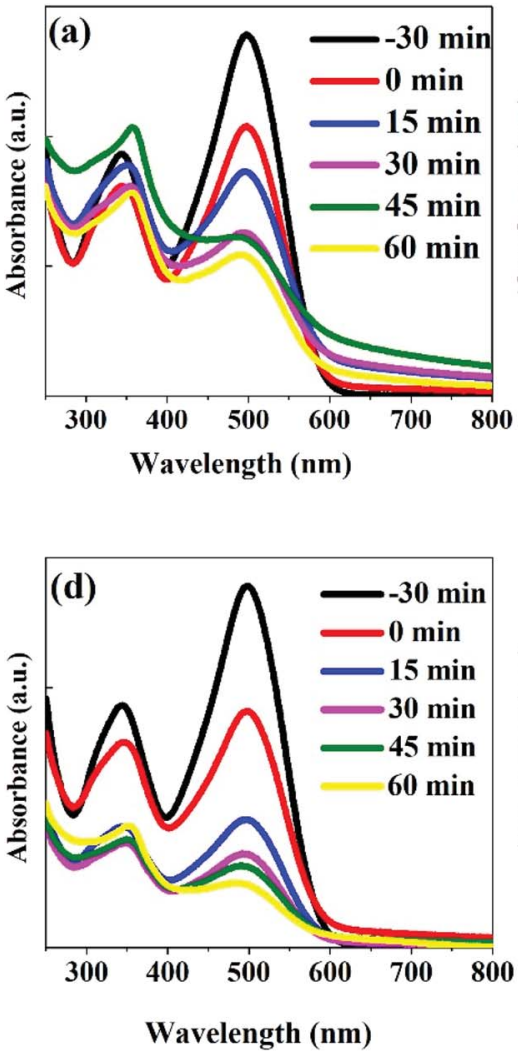
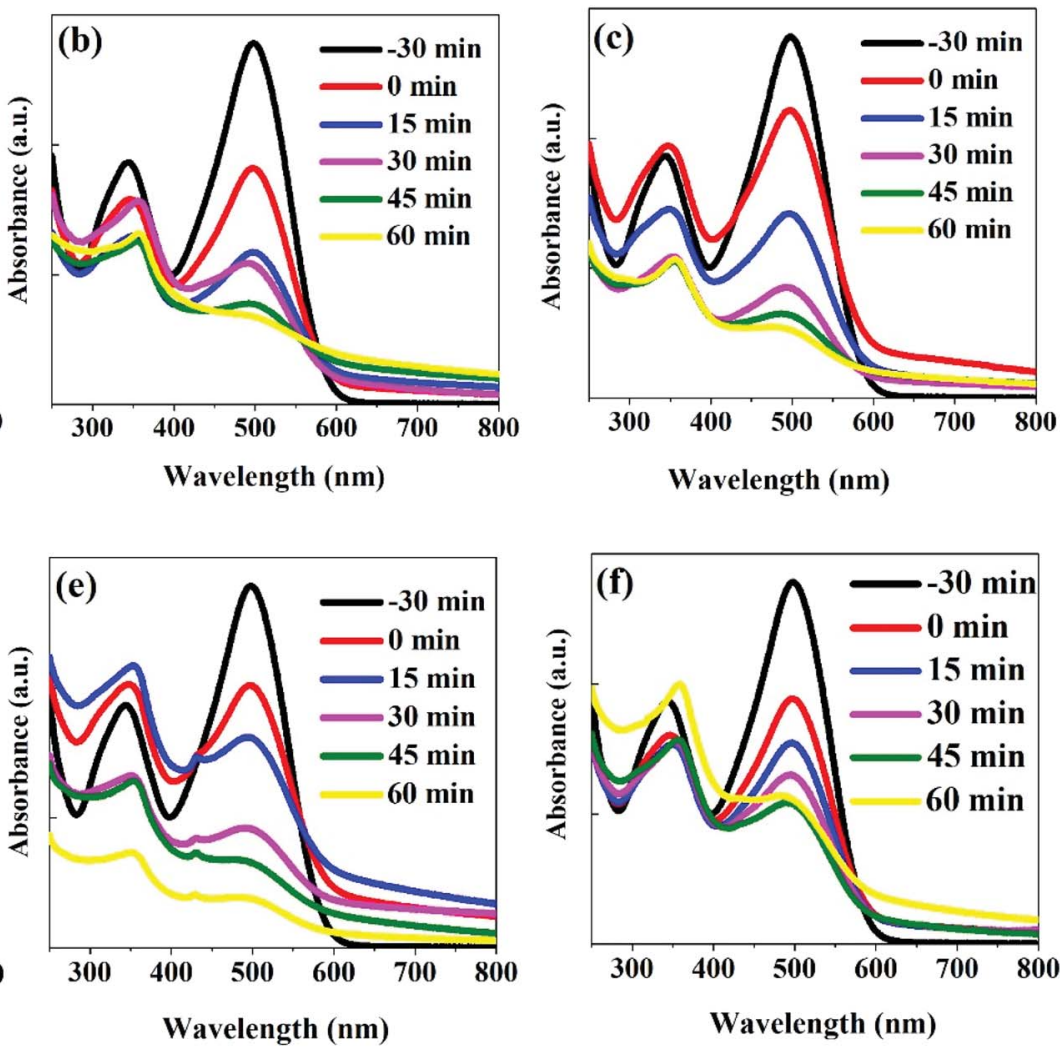

Fig. 8 UV-Vis absorbance spectra of CR dyes recorded after different photodegradation time intervals using (a) $\mathrm{ZnO}$, (b) $\mathrm{ZnO} / \mathrm{GR}$, (c) $\mathrm{ZnO} / \mathrm{Ag} /$ Agl, (d) $\mathrm{ZnO} / \mathrm{GR} / \mathrm{Ag} / \mathrm{Agl}$ (10\%), (e) $\mathrm{ZnO} / \mathrm{GR} / \mathrm{Ag} / \mathrm{Agl}$ (20\%), and (f) ZnO/GR/Ag/Agl (30\%) photocatalysts. The spectra marked by "-30 min" were recorded for the CR only. The spectra marked by "0 min" were recorded for the samples kept in darkness for 30 min (no irradiation).

an excellent adsorption capacity. This plays a key role in the present nanocomposites where the enhanced dye adsorption on the surface of the photocatalysts strongly increases their photocatalytic performance ${ }^{49}$ With increasing irradiation time, the main absorbance peak at $497 \mathrm{~nm}$ related to CR reduces progressively, verifying the degradation of the CR dye. After $60 \mathrm{~min}$ irradiation, the absorbance peak for the $\mathrm{ZnO} / \mathrm{GR} / \mathrm{Ag} / \mathrm{AgI}$ (20\%) nanocomposite has almost disappeared (Fig. 8(e)). In contrast, the variation of the absorbance peaks for the $\mathrm{ZnO}$, $\mathrm{ZnO} / \mathrm{GR}$, and $\mathrm{ZnO} / \mathrm{Ag} / \mathrm{AgI}$ samples were small as shown in Fig. 8(a, b, and c), respectively. The enhanced photocatalytic performance of $\mathrm{ZnO} / \mathrm{GR} / \mathrm{Ag} / \mathrm{AgI}$ nanocomposites can be assigned to the synergistic effect of $\mathrm{ZnO} / \mathrm{GR}$ and $\mathrm{Ag} / \mathrm{AgI}$, and the improved charge transfer ability of the photo-generated carriers at their interfaces as discussed in detail below.

The photodegradation efficiency (\%) was calculated according to eqn (1) and the results are shown in Fig. 9.

$$
\text { Degradation }(\%)=\frac{A_{0}-A}{A_{0}} \times 100
$$

where $A_{0}$ is the initial absorbance of the dye, and $A$ is the absorbance after a specific irradiation time.

Fig. 9(a) displays the calculated degradation efficiency of the $\mathrm{ZnO}, \mathrm{ZnO} / \mathrm{GR}, \mathrm{ZnO} / \mathrm{Ag} / \mathrm{AgI}$, and $\mathrm{ZnO} / \mathrm{GR} / \mathrm{Ag} / \mathrm{AgI}$ samples under solar irradiation. In the absence of any photocatalyst, the photolysis of the $\mathrm{CR}$ is negligible, which shows that this pollutant has high stability during extended periods of irradiation. In contrast, the usage of $\mathrm{ZnO}$ NPs and $\mathrm{ZnO} / \mathrm{GR}$ nanocomposites enhance the photocatalytic performance. In particular, the incorporation of GR leads to a significantly higher photodegradation efficiency of $75 \%$ compared to $58 \%$ for pure ZnO NPs, an effect primarily attributed to inhibition of the recombination of photogenerated $\mathrm{e}^{-} / \mathrm{h}^{+}$pairs during the photocatalytic reaction. However, in comparison to pure $\mathrm{ZnO}$ $\mathrm{NPs}$, and $\mathrm{ZnO} / \mathrm{GR}$, the plasmonic $\mathrm{ZnO} / \mathrm{Ag} / \mathrm{AgI}$ and $\mathrm{ZnO} / \mathrm{GR} / \mathrm{Ag} /$ AgI nanocomposites show superior photocatalytic activities for CR photodegradation. This important result originates first of all from the addition of $\mathrm{Ag} / \mathrm{AgI}$ which increases the absorption of photons, and thus, the number of photogenerated $\mathrm{e}^{-} / \mathrm{h}^{+}$ pairs in the visible region of the solar spectrum. Interestingly, the photocatalytic performance of the plasmonic nanocomposites depends strongly on the Ag/AgI weight ratio. The $\mathrm{ZnO} / \mathrm{GR} / \mathrm{Ag} / \mathrm{AgI}$ (20\%) nanocomposite exhibits the highest photodegradation efficiency reaching $90 \%$ after $60 \mathrm{~min}$ of irradiation. However, with increasing $\mathrm{Ag} / \mathrm{AgI}$ weight ratio up to $30 \%$, the photodegradation efficiency decreased to only $60 \%$ after 60 minutes of irradiation. This drop in efficiency can be explained by the excess of $\mathrm{Ag} / \mathrm{AgI}$ acting as efficient recombination centers. Moreover, the $\mathrm{Ag} / \mathrm{AgI}$ species might cover the active sites on the nanocomposite surface and thereby passivate 
the effective junctions between the counterparts which lead to a reduced charge separation efficiency in $\mathrm{ZnO} / \mathrm{GR} / \mathrm{Ag} / \mathrm{AgI}$ (30\%) sample. A specific content of Ag/AgI is thus crucial for optimizing the photocatalytic performance of plasmonic $\mathrm{ZnO} / \mathrm{GR} /$ Ag/AgI nanocomposites.

The photodegradation of the CR dye may follow two different processes of direct mineralization or stepwise $N$-deethylation. The direct mineralization involves gaseous end-products such as $\mathrm{CO}_{2}, \mathrm{NO}_{3}$, and $\mathrm{NO}_{x}$, whereas the stepwise $\mathrm{N}$-deethylation leads to a destruction of the conjugated structure of the CR dye which results in a complete degradation. In our photodegradation experiments, the absorption of the $\mathrm{CR}$ is decreasing with time without any shift in the absorbance spectrum after 60 min of irradiation (Fig. 8(e)). This suggests that the $\mathrm{CR}$ dye was directly mineralized, producing endproducts of $\mathrm{CO}_{2}, \mathrm{NO}_{3}$, and $\mathrm{NO}_{x} .^{15,50,51}$

To further reveal the photoreactivity mechanisms involved in photodegradation of the CR dye with the $\mathrm{ZnO} / \mathrm{GR} / \mathrm{Ag} / \mathrm{AgI}(20 \%)$ nanocomposite, trapping experiments were performed to identify the reactive species that are involved in the photocatalytic mechanisms. For this purpose, ethylenediaminetetraacetic acid (EDTA), benzoquinone (BQ) and 2-propanol were used as scavengers for $\mathrm{h}^{+}$, superoxide radicals, and hydroxyl radicals, respectively. ${ }^{52-55}$ As shown in Fig. 9(b), the photodegradation process was suppressed with the addition of BQ due to the quenching of the superoxide radicals, indicating that the superoxide radicals are the main reactive species involved in the photodegradation of the CR dye. Also, it was observed that the addition of 2-propanol showed partial inhabitation of the degradation of the CR, suggesting that the hydroxyl radicals also play an important role for the photocatalytic performance. Surprisingly, the addition of EDTA did not have any noticeable effect at the beginning of the degradation process. However, the quenching of holes due to the addition of the EDTA gradually increased after $30 \mathrm{~min}$ of irradiation.

To further investigate the photocatalytic stability and reusability of the $\mathrm{ZnO} / \mathrm{GR} / \mathrm{Ag} / \mathrm{AgI}$ (20\%) nanocomposite, recycling tests of the efficiency for photodegradation of CR were performed. After four successive degradation experiments (Fig. 9(c)), only a small reduction in the efficiency was observed, indicating an excellent stability of the nanocomposite.

To rule out any effects of photosensitization of the CR dye under visible light, the photocatalytic performance of the various nanocomposites in this work was investigated for colourless phenol $\left(0.02 \mathrm{~g} \mathrm{~L}^{-1}\right)$, well known to be insensitive to visible light. A mixture of $100 \mathrm{~mL}$ of a phenol solution with
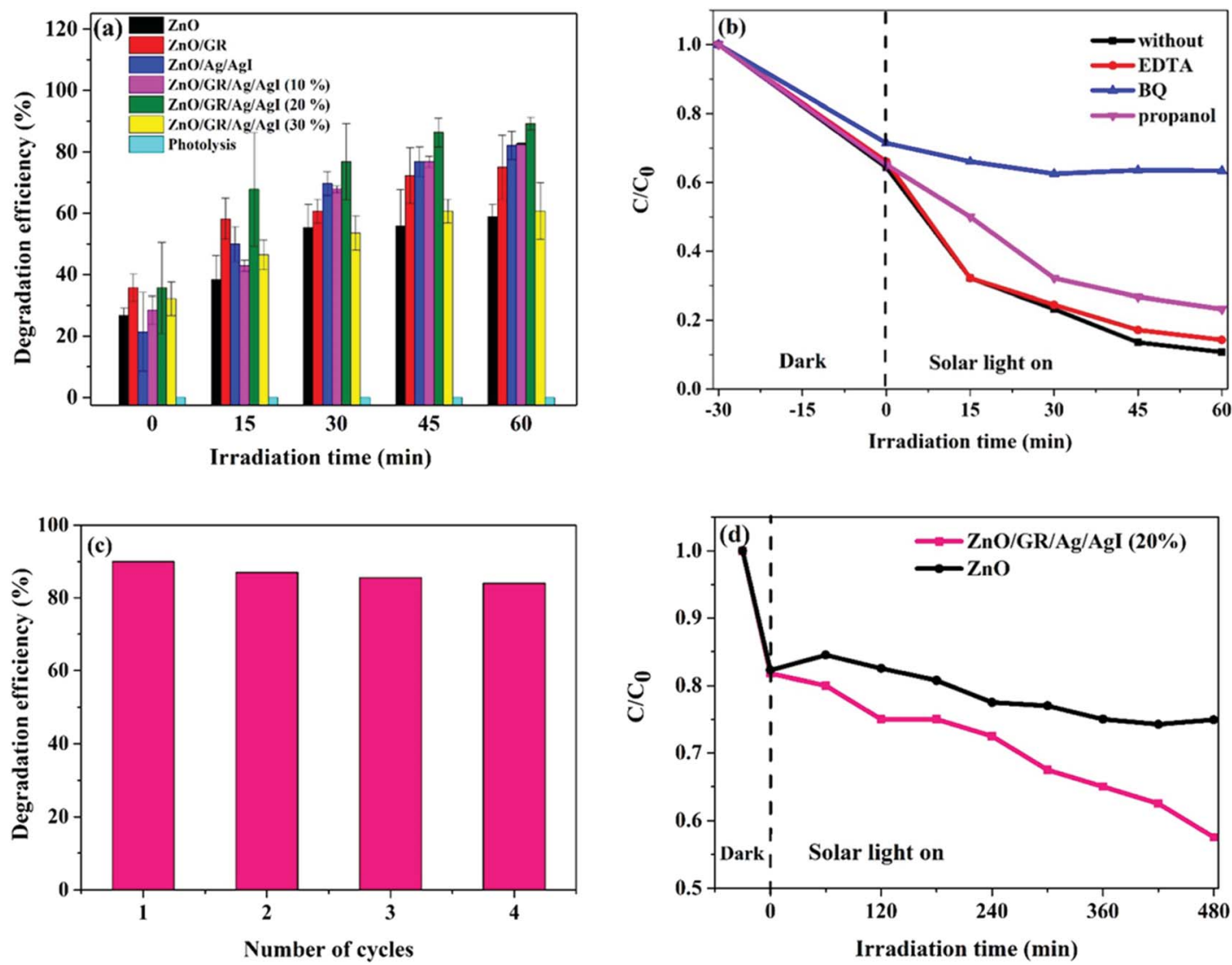

Fig. 9 (a) Photodegradation efficiency of $\mathrm{CR}$ dyes using $\mathrm{ZnO}, \mathrm{ZnO} / \mathrm{GR}, \mathrm{ZnO} / \mathrm{Ag} / \mathrm{Agl}$ and $\mathrm{ZnO} / \mathrm{GR} / \mathrm{Ag} / \mathrm{Agl}$ photocatalysts with different weight percentage of $\mathrm{Ag} / \mathrm{Agl}$, (b) photocatalytic activities of CR with ZnO/GR/Ag/Agl (20\%) nanocomposite in the presence of different scavengers, (c) recycling of $\mathrm{ZnO} / \mathrm{GR} / \mathrm{Ag} / \mathrm{Agl}(20 \%)$ nanocomposite during degradation of $\mathrm{CR}$, and (d) photodegradation of phenol with $\mathrm{ZnO}$ and $\mathrm{ZnO} / \mathrm{GR} / \mathrm{Ag} / \mathrm{Agl}$ (20\%) nanocomposite. 
$0.05 \mathrm{~g}$ of the respective nanocomposite was stirred for $30 \mathrm{~min}$ in dark to reach the adsorption-desorption equilibrium. Then UVVis absorbance spectra of the different mixtures were recorded in 60 min time intervals. The absorption peak of phenol at $270 \mathrm{~nm}$ was used to calculate the concentration of phenol at each time (Fig. 9(d)). It is obvious that the concentration of phenol is decreasing gradually with irradiation time, indicating the decomposition of phenol. In comparison to pure ZnO NPs, the $\mathrm{ZnO} / \mathrm{GR} / \mathrm{Ag} / \mathrm{AgI}(20 \%)$ nanocomposite shows a superior efficiency for photodegradation of phenol. This result also implies that the effect of dye sensitization on the degradation efficiency is small for both phenol and CR.

To develop a deeper understanding of the photocatalytic mechanisms, the apparent reaction constant for each photocatalyst was investigated according to the Langmuir-Hinshelwood's pseudo-first order kinetics model ${ }^{56}$ shown in eqn (2) below.

$$
K_{\mathrm{app}}=\frac{\ln \left[\frac{C_{0}}{C(t)}\right]}{t},
$$

where $K_{\text {app }}$ is the apparent reaction constant $\left(\min ^{-1}\right), t$ is the irradiation time (min), $C_{0}$ is the initial concentration $\mathrm{mol} \mathrm{L}^{-1}$ of the dye, and $C(t)$ is the concentration $\mathrm{mol} \mathrm{L}^{-1}$ of the dye after irradiation time $t$. The plot of $\ln \left[\frac{C_{0}}{C(t)}\right]$ versus irradiation time is shown in Fig. 10(a) and found to be in excellent agreement with the Langmuir-Hinshelwood model. The degradation rate constant of CR is found to be $105 \times 10^{-4}, 160 \times 10^{-4}, 208 \times$ $10^{-4}, 208 \times 10^{-4}, 266 \times 10^{-4}$, and $110 \times 10^{-4} \mathrm{~min}^{-1}$ for $\mathrm{ZnO}$, $\mathrm{ZnO} / \mathrm{GR}, \mathrm{ZnO} / \mathrm{Ag} / \mathrm{AgI}, \mathrm{ZnO} / \mathrm{GR} / \mathrm{Ag} / \mathrm{AgI}$ (10\%), ZnO/GR/Ag/AgI (20\%), and $\mathrm{ZnO} / \mathrm{GR} / \mathrm{Ag} / \mathrm{AgI}(30 \%)$, respectively. It is clear that the degradation rate constant for $\mathrm{ZnO} / \mathrm{GR} / \mathrm{Ag} / \mathrm{AgI}(20 \%)$ is superior to those of the other GR-based nanocomposites.

In Table 1 we show a comparison of the degradation efficiency of different reported GR-based photocatalysts. Summarized, this survey demonstrates that the present plasmonic $\mathrm{ZnO} /$ GR/Ag/AgI (20\%) nanocomposite has very high photodegradation efficiency with respect to the irradiation time of the photocatalytic reaction and with reasonable degradation rate constant.

3.2.2 Proposed photocatalytic mechanism. To experimentally probe the electronic band structure of $\mathrm{ZnO} / \mathrm{Gr} / \mathrm{Ag} / \mathrm{AgI}$ nanocomposites, Mott-Schottky analysis of both $\mathrm{ZnO}$ and AgI semiconductors were performed to determine the conduction and valence band edge energies $\left(E_{\mathrm{CB}}\right.$ and $\left.E_{\mathrm{VB}}\right) \cdot{ }^{57,58}$ As readily observed in Fig. 11(a and b), both the $\mathrm{ZnO}$ and AgI samples exhibit capacitance $v s$. potential characteristics consistent with n-type semiconductors. The flat band potentials can be determined from the extrapolation of $1 / C^{2}$ to zero, which found to be $-0.44 \mathrm{~V}$ and $-0.52 \mathrm{~V} v$ s. $\mathrm{Ag} / \mathrm{AgCl}$ (i.e., $-0.24 \mathrm{~V}$ and $-0.32 \mathrm{~V} v$ s. $\mathrm{NHE}$ ) for $\mathrm{ZnO}$ and $\mathrm{AgI}$ semiconductors, respectively. It is worth noted that the flat band potential for n-type semiconductor is placed at $0.1 \mathrm{eV}$ more positive potential than the $E_{\mathrm{CB}}$. Accordingly, $E_{\mathrm{CB}}$ for the $\mathrm{ZnO}$ and $\mathrm{AgI}$ was obtained to be -0.34 and
$-0.42 \mathrm{eV}$, respectively. In addition, considering the band gap values and based on Mullikan theory calculations, ${ }^{59}$ the $E_{\mathrm{VB}}$ of $\mathrm{ZnO}$ and AgI was computed to be $+2.86 \mathrm{eV}$ and $+2.37 \mathrm{eV}$, respectively.

In Fig. 12 we show a schematic of the proposed photocatalytic mechanism deduced from the combined results of the different measurements and analysis methods discussed in this work. In the presence of solar light, $\mathrm{ZnO}$ and AgI simultaneously play a key role in absorbing the solar light. Especially AgI, with its smaller bandgap than ZnO, can efficiently increase the absorption in the visible light region. ${ }^{27}$ When solar light impinges on the $\mathrm{ZnO} / \mathrm{GR} / \mathrm{Ag} / \mathrm{AgI}$ photocatalyst surface, electrons, and holes are generated in the conduction band (CB) and valence band (VB) in $\mathrm{ZnO}$ and AgI, respectively. Owing to the band offsets, the electrons residing in the $\mathrm{CB}$ of $\mathrm{AgI}$ migrate to the $\mathrm{CB}$ of $\mathrm{ZnO}$ and, in a likewise manner, holes in the $\mathrm{VB}$ of $\mathrm{ZnO}$ move to the $\mathrm{VB}$ of AgI. This leads to an efficient charge carrier separation and transportation which mitigates the undesired recombination of charge carriers. In addition, the plasmonic Ag NPs act as efficient generators of electrons and holes when
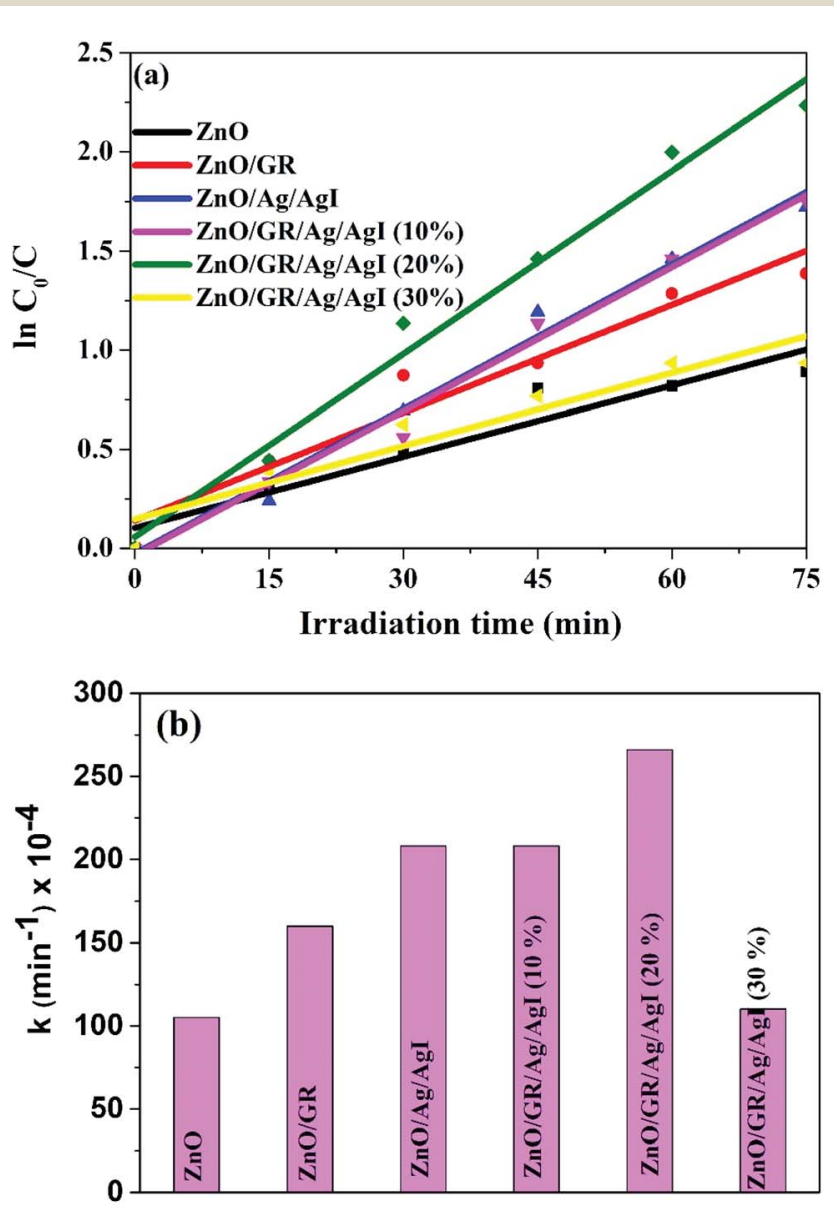

Photocatalyst

Fig. 10 (a) $\ln \left(C_{0} / C\right)$ versus irradiation time, and (b) degradation rate constant of $\mathrm{CR}$ dyes using $\mathrm{ZnO}, \mathrm{ZnO} / \mathrm{GR}, \mathrm{ZnO} / \mathrm{Ag} / \mathrm{Agl}$ and $\mathrm{ZnO} / \mathrm{GR} /$ $\mathrm{Ag} / \mathrm{Agl}$ photocatalysts with a different weight percentage of $\mathrm{Ag} / \mathrm{Agl}$. 
Table 1 Comparison of state-of-the-art GR-based nanocomposites for photodegradation of organic dyes

\begin{tabular}{|c|c|c|c|c|c|c|}
\hline Photocatalyst & Synthesis method & Light source & Dye & $\begin{array}{l}\text { Degradation min/ } \\
\text { efficiency }\end{array}$ & $\begin{array}{l}K_{\text {app }} \\
\left(10^{-2} \min ^{-1}\right)\end{array}$ & Year \\
\hline $\begin{array}{l}\text { AgI-mesoTiO } / \\
4 \mathrm{wt} \% \mathrm{RGO}\end{array}$ & Hummers and ultrasound & $150 \mathrm{~W}$ tungsten lamp & $\begin{array}{l}\text { Methylene } \\
\text { orange }\end{array}$ & $90 / 92 \%$ & - & $\begin{array}{l}2016 \text { (ref. } \\
11)\end{array}$ \\
\hline P25/1 wt\% GR & Modified Hummers method & $500 \mathrm{~W}$ xenon lamp & $\begin{array}{l}\text { Methylene } \\
\text { blue }\end{array}$ & $65 / 65 \%$ & - & $\begin{array}{l}2010 \text { (ref. } \\
60)\end{array}$ \\
\hline $\mathrm{ZnSe} / 1$ wt $\%$ GR & Modified Hummers method & $\begin{array}{l}\text { Solar simulator with a power of } \\
1 \text { sun }\end{array}$ & $\begin{array}{l}\text { Methylene } \\
\text { blue }\end{array}$ & $240 / 99.5 \%$ & 1.27 & $\begin{array}{l}2015 \text { (ref. } \\
61 \text { ) }\end{array}$ \\
\hline $\begin{array}{l}\mathrm{Ag} / \mathrm{Ag}_{2} \mathrm{CO}_{3}-1 \mathrm{wt} \% \\
\mathrm{RGO}\end{array}$ & $\begin{array}{l}\text { Physical mixing and chemical } \\
\text { bath deposition }\end{array}$ & $350 \mathrm{~W}$ xenon lamp & $\begin{array}{l}\text { Methylene } \\
\text { orange }\end{array}$ & $15 / 7 \%$ & 1.80 & $\begin{array}{l}2016 \text { (ref. } \\
62 \text { ) }\end{array}$ \\
\hline $\begin{array}{l}\mathrm{BiVO}_{4} / 5.5 \mathrm{wt} \% \\
\mathrm{RGO} / \mathrm{Bi}_{2} \mathrm{O}_{3}\end{array}$ & Chemical bath deposition & $150 \mathrm{~W}$ metal halide lamp & Bisphenol A & $240 / 60 \%$ & 0.031 & $\begin{array}{l}2017 \text { (ref. } \\
63)\end{array}$ \\
\hline $\mathrm{Ag} / \mathrm{ZnO} / 1 \mathrm{wt} \% \mathrm{GR}$ & $\begin{array}{l}\text { Low-temperature microwave- } \\
\text { assisted solution }\end{array}$ & $300 \mathrm{~W}$ high-pressure $\mathrm{Hg}$ lamp & $\begin{array}{l}\text { Methylene } \\
\text { orange }\end{array}$ & $80 / 99.6 \%$ & 0.5 & $\begin{array}{l}2015 \text { (ref. } \\
64)\end{array}$ \\
\hline $1.78 \mathrm{wt} \%$ RGO-ZnO & Chemical bath deposition & $400 \mathrm{~W} \mathrm{Hg}$ lamp & Rhodamine B & $60 / 61.5 \%$ & - & $\begin{array}{l}2015 \text { (ref. } \\
65)\end{array}$ \\
\hline 3 wt $\%$ GR/ZnO & Hydrolysis deposition & $3 \mathrm{~W}$ LED lamp & X3B & $45 / 80 \%$ & 0.34 & $\begin{array}{l}2015 \text { (ref. } \\
66)\end{array}$ \\
\hline $\mathrm{ZnO} / 10 \mathrm{wt} \% \mathrm{RGO}$ & Hummers and arc discharge & $90 \mathrm{~W}$ halogen light & $\begin{array}{l}\text { Methylene } \\
\text { orange }\end{array}$ & $90 / 100 \%$ & 0.47 & $\begin{array}{l}2015 \text { (ref. } \\
67 \text { ) }\end{array}$ \\
\hline $1 \mathrm{wt} \% \mathrm{GR} / \mathrm{ZnO}$ & Hydrothermal & $250 \mathrm{~W}$ mercury lamp & $\begin{array}{l}\text { Methylene } \\
\text { blue }\end{array}$ & $450 / 90 \%$ & - & $\begin{array}{l}2016 \text { (ref. } \\
68)\end{array}$ \\
\hline $\mathrm{Ag}_{2} \mathrm{CrO}_{4}-1 \mathrm{wt} \% \mathrm{GR}$ & Precipitation & $300 \mathrm{~W}$ xenon lamp & $\begin{array}{l}\text { Methylene } \\
\text { blue }\end{array}$ & $15 / 50 \%$ & 2.80 & $\begin{array}{l}2015 \text { (ref. } \\
69)\end{array}$ \\
\hline $\begin{array}{l}\mathrm{ZnO} / 1 \mathrm{wt} \% \mathrm{GR} / \mathrm{Ag} / \\
\mathrm{AgI}\end{array}$ & $\begin{array}{l}\text { Ultrasonic-assisted } \\
\text { hydrothermal }\end{array}$ & $\begin{array}{l}\text { Solar simulator ( } 100 \mathrm{~W} \text { xenon } \\
\text { lamp with a power of } 1 \text { sun) }\end{array}$ & Congo red & $60 / 90 \%$ & 2.66 & $\begin{array}{l}\text { Current } \\
\text { work }\end{array}$ \\
\hline
\end{tabular}
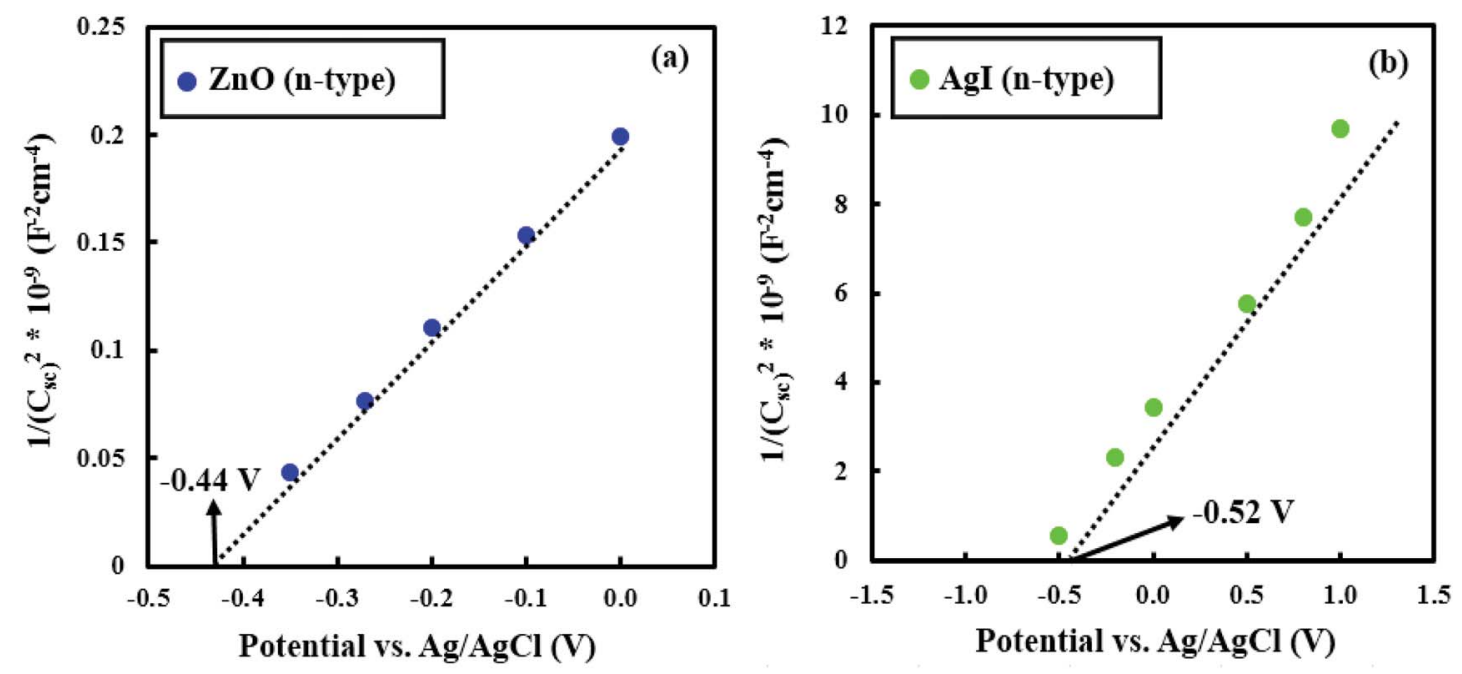

Fig. 11 Mott-Schottky plots for (a) ZnO and (b) Agl samples.

excited by visible light via the SPR effect. These generated electrons are subsequently injected into the CB of AgI and ZnO, respectively. ${ }^{15,37}$ Subsequently, the photogenerated electrons are transferred from the $\mathrm{CB}$ of $\mathrm{ZnO}$ to the GR. The GR plays a dual role of electron acceptor and transporter, which improve the photocatalytic behavior of the nanocomposite under solar irradiation. The efficient transfer of electrons and the reduction of the recombination rate at the surface of the photocatalyst strongly enhance the photocatalytic efficiency. The trapped electrons react with oxygen molecules to produce superoxide radicals that subsequently get converted into hydroxyl radicals through multi-electron reduction reactions. Finally, these active species can react with pollutant (dye) molecules and decompose them into $\mathrm{H}_{2} \mathrm{O}, \mathrm{CO}_{2}$, and mineral compounds. The photoinduced holes can directly oxidize the adsorbed dye molecules to produce degraded products. As a result, the high photodegradation efficiency of $\mathrm{ZnO} / \mathrm{GR} / \mathrm{Ag} / \mathrm{AgI}$ nanocomposites is related to the uniform distribution of the nanoparticles at the surface of the GR nanosheets, and strong synergy effects 


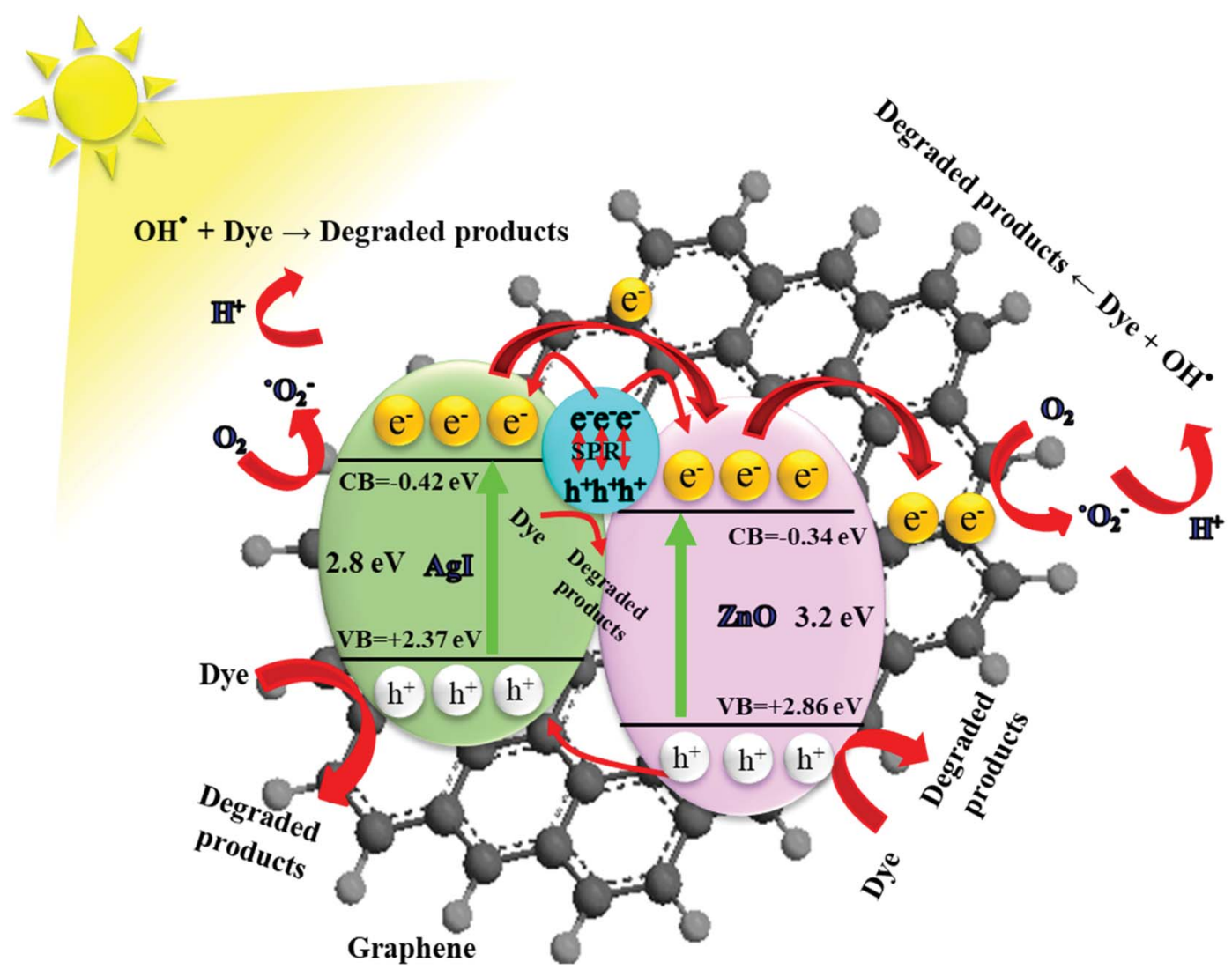

Fig. 12 Schematic diagram showing the energy band structure and possible $\mathrm{e}^{-} / \mathrm{h}^{+}$pair separation and charge carrier transport mechanisms in $\mathrm{ZnO} / \mathrm{GR} / \mathrm{Ag} / \mathrm{Agl}$ nanocomposites.

between GR, ZnO NPs, and Ag/AgI that favours interfacial charge transfer and prevents $\mathrm{e}^{-} / \mathrm{h}^{+}$recombination.

\section{Conclusion}

In summary, we have reported on a novel low-temperature chemical route, assisted by ultrasonication, to prepare $\mathrm{ZnO} /$ GR/Ag/AgI nanocomposites for state-of-the-art photocatalytic performance for degradation of CR and phenol. The prepared plasmonic nanocomposites have been characterized by various techniques to unravel their structural, morphological, electrical, optical and photocatalytic properties. The synthesized $\mathrm{ZnO} / \mathrm{GR} / \mathrm{Ag} / \mathrm{AgI}$ (20\%) nanocomposite exhibits the highest photodegradation efficiency $(90 \%)$ and the highest degradation constant rate $\left(308 \times 10^{-4} \mathrm{~min}^{-1}\right)$ for degradation of CR dye. The key advantages of the optimized nanocomposites include increased light absorption in the visible range due to a strong plasmonic resonance effect involving metallic $\mathrm{Ag}^{0}$, and to the improved electronic transfer due to hybridization with graphene. In addition, the nanoparticles in the plasmonic nanocomposite facilitate an effective charge separation of the photoexcited charge carriers, mitigating $\mathrm{e}^{-} / \mathrm{h}^{+}$pair recombination. The scavenger experiments suggest that superoxide and hydroxyl radicals are responsible for the photodegradation of CR. The recycling test confirms a sufficient durability of the nanocomposite. We believe that the proposed plasmonic nanocomposites are promising for high photocatalytic performance applications such as removal of organic and inorganic pollutants, photoelectrochemistry and water oxidation.

\section{Conflicts of interest}

There are no conflicts of interest to declare.

\section{Acknowledgements}

The authors acknowledge the Department of Science and Technology (ITN) at Campus Norrköping, Linköping University, Sweden for partial financial support. The Knut and Alice Wallenberg Foundation is acknowledged for support of the Electron Microscopy Laboratory at Linköping University.

\section{References}

1 S. P. Lonkar, V. V. Pillai and S. M. Alhassan, Sci. Rep., 2018, 8, 13401.

2 D. Barreca, G. Carraro, A. Gasparotto, C. Maccato, T. Altantzis, C. Sada, K. Kaunisto, T.-P. Ruoko and S. Bals, Adv. Mater. Interfaces, 2017, 4, 1700161.

3 H. Zhang, G. Chen and D. W. Bahnemann, J. Mater. Chem., 2009, 19, 5089. 
4 H. Wang, X. Liu and S. Han, CrystEngComm, 2016, 18, 19331943.

5 S. Kumar, A. Kumar, A. Kumar, R. Balaji and V. Krishnan, ChemistrySelect, 2018, 3, 1919-1932.

6 A. Kumar, V. Sharma, S. Kumar, A. Kumar and V. Krishnan, Surf. Interfaces, 2018, 11, 98-106.

7 W. Zhong, S. Shen, S. Feng, Z. Lin, Z. Wang and B. Fang, CrystEngComm, 2018, 20, 7851-7856.

8 Y. Liu, S. Shen, J. Zhang, W. Zhong and X. Huang, Appl. Surf. Sci., 2019, 478, 762-769.

9 G. Liao, Y. Gong, L. Zhang, H. Gao, G.-J. Yang and B. Fang, Energy Environ. Sci., 2019, 12, 2080-2147.

10 J. Xu, Y. Cui, Y. Han, M. Hao and X. Zhang, RSC Adv., 2016, 6, 96778-96784.

11 R. Vinoth, P. Karthik, C. Muthamizhchelvan, B. Neppolian and M. Ashokkumar, Phys. Chem. Chem. Phys., 2016, 18, 5179-5191.

12 A. Kumar, K. L. Reddy, S. Kumar, A. Kumar, V. Sharma and V. Krishnan, ACS Appl. Mater. Interfaces, 2018, 10, 1556515581.

13 H. Sun and S. Wang, Energy Fuels, 2014, 28, 22-36.

14 S. Lee, D. A. Reddy and T. Kyu Kim, RSC Adv., 2016, 6, 3718037188.

15 J. Choi, D. A. Reddy, M. J. Islam, R. Ma and T. K. Kim, J. Alloys Compd., 2016, 688, 527-536.

16 N. Zhang, Y. Zhang and Y.-J. Xu, Nanoscale, 2012, 4, 57925813.

17 Q. Xiang, J. Yu and M. Jaroniec, Chem. Soc. Rev., 2012, 41, 782-796.

18 B. Li, T. Liu, Y. Wang and Z. Wang, J. Colloid Interface Sci., 2012, 377, 114-121.

19 B. Li and H. Cao, J. Mater. Chem., 2011, 21, 3346-3349.

20 E. Chalangar, H. Machhadani, S.-H. Lim, K. F. Karlsson, O. Nur, M. Willander and H. Pettersson, Nanotechnology, 2018, 29, 415201.

21 Z. Tian, S. Bai, K. Cao and J. Li, Mater. Express, 2016, 6, 437443.

22 S. Y. Sawant and M. Hwan Cho, RSC Adv., 2015, 5, 9778897797.

23 K. L. Reddy, S. Kumar, A. Kumar and V. Krishnan, J. Hazard. Mater., 2019, 367, 694-705.

24 A. Kumar, K. Kumar and V. Krishnan, Mater. Lett., 2019, 245, $45-48$.

25 D. A. Reddy, S. Lee, J. Choi, S. Park, R. Ma, H. Yang and T. K. Kim, Appl. Surf. Sci., 2015, 341, 175-184.

26 G. Li, Y. Wang and L. Mao, RSC Adv., 2014, 4, 53649-53661.

27 M. Pirhashemi and A. Habibi-Yangjeh, Ceram. Int., 2017, 43, 13447-13460.

28 N. Güy and M. Özacar, J. Photochem. Photobiol., A, 2019, 370, 1-11.

29 G. Liao, J. Fang, Q. Li, S. Li, Z. Xu and B. Fang, Nanoscale, 2019, 11, 7062-7096.

30 W. Jiang, C. An, J. Liu, S. Wang, L. Zhao, W. Guo and J. Liu, Dalton Trans., 2013, 43, 300-305.

31 J. Yang, X. Zhao, X. Shan, H. Fan, L. Yang, Y. Zhang and X. Li, J. Alloys Compd., 2013, 556, 1-5.
32 M. Pirhashemi and A. Habibi-Yangjeh, J. Colloid Interface Sci., 2017, 491, 216-229.

33 B. Saravanakumar, R. Mohan and S.-J. Kim, Mater. Res. Bull., 2013, 48, 878-883.

34 D. Fu, G. Han, Y. Chang and J. Dong, Mater. Chem. Phys., 2012, 132, 673-681.

35 A. Monshi, M. R. Foroughi and M. R. Monshi, World J. Nano Sci. Eng., 2012, 02, 154-160.

36 B. Qiu, Y. Zhou, Y. Ma, X. Yang, W. Sheng, M. Xing and J. Zhang, Sci. Rep., 2015, 5, 8591.

37 S. Lu, H. Wang, J. Zhou, X. Wu and W. Qin, Nanoscale, 2017, 9, 1184-1192.

38 V. Etacheri, R. Roshan and V. Kumar, ACS Appl. Mater. Interfaces, 2012, 4, 2717-2725.

39 H. Alnoor, G. Pozina, V. Khranovskyy, X. Liu, D. Iandolo, M. Willander and O. Nur, J. Appl. Phys., 2016, 119, 165702.

40 D. K. Mishra, J. Mohapatra, M. K. Sharma, R. Chattarjee, S. K. Singh, S. Varma, S. N. Behera, S. K. Nayak and P. Entel, J. Magn. Magn. Mater., 2013, 329, 146-152.

41 H. Moussa, E. Girot, K. Mozet, H. Alem, G. Medjahdi and R. Schneider, Appl. Catal., B, 2016, 185, 11-21.

42 A. Kumar, L. Rout, L. S. K. Achary, S. Keshari Mohanty and P. Dash, New J. Chem., 2017, 41, 10568-10583.

43 K. Dai, J. Lv, L. Lu, C. Liang, L. Geng and G. Zhu, Mater. Chem. Phys., 2016, 177, 529-537.

44 H. N. Tien, V. H. Luan, L. T. Hoa, N. T. Khoa, S. H. Hahn, J. S. Chung, E. W. Shin and S. H. Hur, Chem. Eng. J., 2013, 229, 126-133.

45 C. Hu, T. Peng, X. Hu, Y. Nie, X. Zhou, J. Qu and H. He, J. Am. Chem. Soc., 2010, 132, 857-862.

46 M. R. Phillips, O. Gelhausen and E. M. Goldys, Phys. Status Solidi A, 2004, 201, 229-234.

47 S. Choi, M. R. Phillips, I. Aharonovich, S. Pornsuwan, B. C. C. Cowie and C. Ton-That, Adv. Opt. Mater., 2015, 3, 821-827.

48 V. Khranovskyy, V. Lazorenko, G. Lashkarev and R. Yakimova, J. Lumin., 2012, 132, 2643-2647.

49 B. Neppolian, A. Bruno, C. L. Bianchi and M. Ashokkumar, Ultrason. Sonochem., 2012, 19, 9-15.

50 J. Choi, D. A. Reddy and T. K. Kim, Ceram. Int., 2015, 41, 13793-13803.

51 D. Amaranatha Reddy, R. Ma, M. Y. Choi and T. K. Kim, Appl. Surf. Sci., 2015, 324, 725-735.

52 T. T. H. Tran, H. Kosslick, A. Schulz and Q. L. Nguyen, Adv. Nat. Sci.: Nanosci. Nanotechnol., 2017, 8, 015011.

53 L. Hou, H. Zhang and X. Xue, Sep. Purif. Technol., 2012, 84, 147-152.

54 A. L. Teel and R. J. Watts, J. Hazard. Mater., 2002, 94, 179189.

55 D. Amaranatha Reddy, J. Choi, S. Lee, R. Ma and T. Kyu Kim, RSC Adv., 2015, 5, 67394-67404.

56 Y. Li, X. Li, J. Li and J. Yin, Water Res., 2006, 40, 1119-1126. 57 N. Sedaghati, A. Habibi-Yangjeh, M. Pirhashemi and S. Vadivel, J. Photochem. Photobiol., A, 2019, 384, 112066.

58 S. Feizpoor, A. Habibi-Yangjeh, I. Ahadzadeh and K. Yubuta, Adv. Powder Technol., 2019, 30, 1183-1196.

59 A. H. Nethercot, Phys. Rev. Lett., 1974, 33, 1088-1091. 
60 H. Zhang, X. Lv, Y. Li, Y. Wang and J. Li, ACS Nano, 2010, 4, 380-386.

61 S. H. Hsieh, W. J. Chen and T. H. Yeh, Appl. Surf. Sci., 2015, 358, 63-69.

62 S. Song, B. Cheng, N. Wu, A. Meng, S. Cao and J. Yu, Appl. Catal., B, 2016, 181, 71-78.

63 P. Qiu, B. Park, J. Choi, M. Cui, J. Kim and J. Khim, J. Alloys Compd., 2017, 706, 7-15.

64 P. Dou, F. Tan, W. Wang, A. Sarreshteh, X. Qiao, X. Qiu and J. Chen, J. Photochem. Photobiol., A, 2015, 302, 17-22.
65 T. N. Reddy, J. Manna and R. K. Rana, ACS Appl. Mater. Interfaces, 2015, 35, 19684-19690.

66 X. Wu, L. Wen, K. Lv, K. Deng, D. Tang, H. Ye, D. Du, S. Liu and M. Li, Appl. Surf. Sci., 2015, 358, 130-136.

67 A. A. Ashkarran and B. Mohammadi, Appl. Surf. Sci., 2015, 342, 112-119.

68 E. Rokhsat and O. Akhavan, Appl. Surf. Sci., 2016, 371, 590595.

69 D. Xu, B. Cheng, S. Cao and J. Yu, Appl. Catal., B, 2015, 164, 380-388. 